\title{
Identifying a network of brain regions involved in aversion-related processing: a cross-species translational investigation
}

\section{Dave J. Hayes* and Georg Northoff}

Mind, Brain Imaging and Neuroethics Research Unit, Institute of Mental Health Research, University of Ottawa, Ottawa, ON, Canada

\section{Edited by:}

John J. Foxe, Albert Einstein College of Medicine, USA

\section{Reviewed by:}

Rodrigo N. Romcy-Pereira, Federal University of Espírito Santo, Brazil Janina Seubert, Monell Chemical Senses Center, USA

\section{*Correspondence}

Dave J. Hayes, Mind, Brain Imaging and Neuroethics, Institute of Mental Health Research, Royal Ottawa Health Care Group, University of Ottawa, 1145 Carling Avenue, Room 6441, Ottawa, ON, Canada K1Z 7K4. e-mail:david.hayes@rohcg.on.ca
The ability to detect and respond appropriately to aversive stimuli is essential for all organisms, from fruit flies to humans. This suggests the existence of a core neural network which mediates aversion-related processing. Human imaging studies on aversion have highlighted the involvement of various cortical regions, such as the prefrontal cortex, while animal studies have focused largely on subcortical regions like the periaqueductal gray and hypothalamus. However, whether and how these regions form a core neural network of aversion remains unclear. To help determine this, a translational cross-species investigation in humans (i.e., meta-analysis) and other animals (i.e., systematic review of functional neuroanatomy) was performed. Our results highlighted the recruitment of the anterior cingulate cortex, the anterior insula, and the amygdala as well as other subcortical (e.g., thalamus, midbrain) and cortical (e.g., orbitofrontal) regions in both animals and humans. Importantly, involvement of these regions remained independent of sensory modality. This study provides evidence for a core neural network mediating aversion in both animals and humans. This not only contributes to our understanding of the trans-species neural correlates of aversion but may also carry important implications for psychiatric disorders where abnormal aversive behavior can often be observed.

\section{Keywords: meta-analysis, translational, aversion, imaging, animal models}

\section{INTRODUCTION}

\section{BACKGROUND ON AVERSION}

The ability to detect and respond appropriately to potentially harmful stimuli is essential to the well-being and self-preservation of all organisms. Avoidance behavior can be observed in both humans and animals. Even organisms with relatively simple nervous systems (e.g., worms, fruit flies) display avoidance behaviors to aversive stimuli, implying the existence of some evolutionarily conserved mechanisms (Glanzman, 2005; Ardiel and Rankin, 2010). In its most basic form, an aversive event (regardless of its origin) is one that an organism will expend energy to minimize or avoid; in this context, it is operationally opposite to reward (Wise, 2004). The occurrence of such behavior across higherand lower-order species allows one to assume the existence of a basic or core neural network mediating aversion. For instance, in a recent review paper, Seymour et al. (2007) suggested that regions such as the prefrontal, orbitofrontal, and insular cortices

\footnotetext{
Abbreviations: ACC, anterior cingulate cortex; AI, anterior insula; amyg, amygdala; BNST, bed $\mathrm{n}$ of the stria terminalis; ctx, cortex; d, dorsal; DMPFC, dorsomedial prefrontal ctx; DR, dorsal raphe; DS, dorsal striatum; Hab, habenula; Hipp, hippocampal area; Hyp, hypothalamus; IC, inferior colliculus; IL, infralimbic ctx; Ins, insula; lat, lateral; LC, locus coeruleus; n, nucleus; NAc, nucleus accumbens; NTS, n of the solitary tract; OFC, orbital frontal ctx, PAG, periaqueductal gray; Parahipp, parahippocampal gyrus; PBN, parabrachial n; PFC, prefrontal ctx; PL, prelimbic; RTG, rostral temporal gyri; SC, superior colliculus; Sens, sensory ctx; Sep, septal n; SMA, secondary motor area; Thal, thalamus; VLOFC, ventrolateral orbitofrontal ctx; VTA, ventral tegmental area.
}

(along with other regions such as the amygdala and basal ganglia) were essential in regulating the effects and actions associated with social aversion. The main hypothesis of the present investigation is that there are a number of brain regions which are initially involved in the basic processing of aversive stimuli, as empirical evidence for such a core aversion network remains to be provided.

Human neuroimaging studies have been key in understanding the role of many predominantly cortical regions (e.g., prefrontal, orbitofrontal, and insular cortices; e.g., Rolls et al., 2008; Meriau et al., 2009) in the processing of aversive stimuli (e.g., by showing subjects aversive pictures or exposing them to mild shocks or uncomfortable temperatures). In addition, some of these studies have also investigated various behavioral and cognitive facets of aversion-related to fear, anxiety, and pain (e.g., Labar et al., 1998; Chua et al., 1999; Ploghaus et al., 1999; Milad et al., 2007). Similar to those studies looking at responses to generally aversive stimuli, these studies also report recruitment of areas such as the medial prefrontal cortex, the amygdala, the insula, and the anterior cingulate cortex (ACC). Such an overlap between activations associated with generally aversive stimuli on the one hand and those associated with fear, anxiety, and pain on the other, suggest an underlying core neural network mediating aversion-related processing. However, given the limited spatial resolution, neuroimaging mainly allows insight into cortical regions while it is less able to provide detailed information about subcortical regions (though a growing number of studies aim to overcome this using imaging sequences 
focused on precise areas of interest; e.g., Prevost et al., 2011). This is particularly relevant if one assumes that aversion-related processing recruits a basic neural network across species, including those with a less developed cortex.

Animal studies on aversion have largely focused on various subcortical regions. In particular, aversion-related studies in animals have highlighted the importance of subcortical areas such as the periaqueductal gray (PAG), hypothalamus, bed nucleus of the stria terminalis (BNST), raphe nuclei, nucleus accumbens/ventral striatum (NAc/VS), and ventral tegmental area (VTA; e.g., Misslin, 2003; Walker et al., 2003; Jhou, 2005; and for a related review see Carlezon and Thomas, 2009). For instance, direct electrical activation of the PAG results in robust aversive/avoidance behaviors and activates other subcortical structures such as the thalamus and hypothalamus (Vianna et al., 2003). However, whether these subcortical regions, in conjunction with the above reported cortical regions, form a core aversion network remains unclear.

The general aim of this study is to investigate the regions involved in aversion-related processing in both humans and nonhuman animals. To this end, we conducted systematic analyses of human and animal data and compared them for neuroanatomical overlaps and differences. Our specific aims were as follows. First, we aimed to conduct a meta-analysis on human imaging data. Based on the previous data, we hypothesized that this meta-analysis would associate activations in the anterior cingulate, amygdalae, anterior insula (AI), and medial or lateral prefrontal cortex with aversion. We focused on the mere passive perception of aversive stimuli (e.g., the viewing of unpleasant pictures; exposure to unpleasant, but non-painful, tactile/thermal stimuli), while excluding studies with more complex task requirements as well as those implicating additional cognitive and behavioral variables (e.g., decision-making tasks, reflex tasks, tasks specifically targeting pain, fear, or anxiety responses).

Our second aim consisted in the systematic investigation of various aversion studies in animals. Given results from prior studies, noted above, we hypothesized the predominant involvement of subcortical regions like the VTA, NAc/VS, BNST, and PAG with aversion. Because the results from both animals and humans could reflect the impact of unspecific effects associated with distinct sensory modalities, we carefully controlled for this potential confound by contrasting the aversive stimuli according to modality [i.e., auditory, tactile, and visual; olfaction (three studies included) and gustation (one study included) were not investigated in the meta-analysis due to too few studies].

Methodologically, the use of a meta-analytical approach allows for the clear distinction of areas which have been identified reliably across numerous studies - in comparison to individual brain imaging studies which may have low power and/or report a high percentage of false positive activations (Wager et al., 2009). As previously demonstrated by our group in the case of depression (Alcaro et al., 2010), the incorporation of animal studies allows for a cross-species comparison and ensures that especially subcortical areas, which may be important for aversion-related processing (but may not be noted in many human imaging studies due to technical limitations), are identified.

\section{MATERIALS AND METHODS AVERSION-RELATED BRAIN ACTIVATION IN HUMANS Literature search}

To form a dataset of coordinates, we conducted multiple PubMed ${ }^{1}$ searches to initially identify all imaging studies - positron emission tomography (PET) and functional magnetic resonance imaging (fMRI) - published from 2000 to February 2010. The search included keywords such as "aversion," "aversive," "avoidance," "fear," "anxiety," "punishment," "reinforcement" (to capture those studies focusing on reward that have also included independently analyzed aversive conditions), "PET," "positron emission tomography," "fMRI," and "functional magnetic resonance imaging." Furthermore we searched the reference list of identified articles and several reviews, including meta-analyses (for example Costafreda et al., 2008; Mechias et al., 2010).

\section{Inclusion and exclusion criteria}

Our main goal was to investigate the basic neural correlates of aversion. Therefore, we included only those studies and contrasts which used the mere passive presentation of aversive stimuli (e.g., the viewing of unpleasant pictures; exposure to unpleasant, but non-painful, tactile/thermal stimuli) but did not require any active responses. Without behavioral measures, the nature of aversive experiences were determined subjectively and often supported through physiological measures such as electrodermal activity. As such, designs whose contrasts involved explicit behavioral tasks, learning tasks, or those that did not include specific comparisons relevant to the current analysis (i.e., involving the passive perceptual component of aversion, independent of explicit cognitive processes, memory, or attention) were excluded. In addition, only studies that reported coordinates from whole-brain analysis were included (although some studies discussed region-of-interest data, those coordinates were not included here).

Most studies investigating responses to specific negative emotions through face-viewing (e.g., angry or sad faces) were also excluded given the social nature of such stimuli and the ambiguous interpretations possible (e.g., inconsistent relationships to empathy or the signaling of physical contamination, for instance related to disgust; e.g., see Anderson et al., 2003; Chakrabarti et al., 2006). For an analysis of such emotional stimuli, showing results consistent with the present study, the reader is referred to the meta-analyses by Fan et al. (2010) and Kober et al. (2008). Studies investigating explicitly social aspects of aversion (e.g., Eisenberger et al., 2003) were also excluded given they typically involve both behavioral responses, as well as other potential confounder variables such as empathy and theory of mind (e.g., Rilling et al., 2004). An extensive list of studies involving conditioned fearful stimuli in both humans (e.g., Bach et al., 2011; Delgado et al., 2011) and animals (e.g., Johnson et al., 2011; Parsons and Davis, 2011) were also excluded to avoid issues pertaining to recent learning effects and complex designs (e.g., involving various temporal and spatial parameters), although the authors acknowledge that these studies often use similar stimuli and their results are largely in line with those reported here. Finally, studies investigating responses

${ }^{1}$ http://www.pubmed.gov 
to painful stimuli were also presently excluded as the unique experience of pain may confound the present results. However, the authors acknowledge that future studies should investigate such studies in this regard.

In addition, to control for the possible confounding effects of using aversive stimuli from different sensory modalities, we contrasted the stimuli according to modality (i.e., auditory, tactile, and visual; olfaction and gustation were not investigated due to too few studies). This resulted in the following contrasts: auditory $><$ tactile, auditory $><$ visual, visual $><$ tactile.

We included studies reporting single group data (i.e., healthy subjects only); thus, we did not consider coordinates reporting a main effect of processing across the control and a clinical group, nor did we consider coordinates relative to functional, psychophysiological, or psychopathological correlations. Studies including individuals with psychiatric illnesses, or a history thereof, those with volumetric abnormalities or brain injuries, those taking any medications or illicit drugs, and those belonging to a group that may result in a sample bias (e.g., war veterans) were excluded. In addition, a large number of studies were excluded due to the absence of coordinates, identification of coordinate systems, and/or incomplete statistical information.

We then individually screened all the articles for the presence of Talairach or Montreal Neurological Institute (MNI) coordinates and tabulated the reported regional foci. We focused on studies that directly compared the activation of aversion-related circuitry in healthy adult subjects. These criteria resulted in the selection of 34 studies (for a total of 427 subjects; $45 \%$ male), which included 44 contrasts (see references for studies included in the meta-analysis). The authors acknowledge that these stringent inclusion/exclusion criteria have prevented the inclusion of many imaging studies investigating the processing associated with the perception of aversive stimuli. We have done this so as to reduce the number of possible confounding variables but acknowledge that some studies may have been overlooked, particularly if they did not use typical aversion-related terminology (e.g., aversion, punishment, negative).

\section{Multilevel kernel density analysis meta-analytic technique}

The benefits of using the multilevel kernel density analysis (MKDA) meta-analytic approach over others, as well as an extensive elaboration of technical considerations, has been covered in-depth elsewhere (Salimi-Khorshidi et al., 2009; Wager et al., 2009). Briefly, MKDA is a coordinate-based meta-analytic method which determines the activation probability of each voxel (to create voxel-based study comparison maps) and contiguous voxel clusters (to create extent-based study comparison maps which identify significant clusters of activation) across the brain. Compared with other meta-analysis methods, MKDA prevents any single study reporting a large number of activations from biasing the results (i.e., the study is the unit of analysis) and weights contrasts based on the quality of the study (e.g., random vs. fixed effects) and the sample size. Peaks from each study were convolved with a spherical kernel of $10 \mathrm{~mm}$ radius; the threshold for statistical significance was determined using a Monte Carlo simulation with 3000 iterations (using 5000 iterations did not alter the results). The voxel size for the present study was $2 \mathrm{~mm} \times 2 \mathrm{~mm} \times 2 \mathrm{~mm}$ (i.e., 1 voxel $=8 \mathrm{~mm}^{3}$ ) and cluster sizes were all greater than 10 voxels $\left(>80 \mathrm{~mm}^{3}\right)$. We have reported peak voxel-wise activations as well as peak cluster-wise activations (which include contiguous voxels significant at $p<0.001$; whole-brain FWE corrected). All results are family wise error rate whole-brain corrected at $p<0.05$. Analyses were performed in Matlab 2009a (Mathworks, Natick, MA, USA) using MKDA software created by Tor Wager².

\section{AVERSION-RELATED BRAIN ACTIVATION IN ANIMALS Literature search}

We conducted multiple PubMed (see text footnote 1) searches to initially identify all non-human animal studies related to aversion ( 235 studies) published in English from 2000 to February 2010. Furthermore we searched the reference list of identified articles and several reviews. The search included keywords such as "aversion," "aversive," "avoidance," "fear," "anxiety," "punishment," "threat," "reinforcement," "c-Fos," "Fos," "immediate early genes," "IEG," "electrophysiology," "positron emission tomography", "PET," "functional magnetic resonance imaging", "fMRI." Of the total studies identified, only those clearly showing altered brain metabolism (e.g., increased/decreased c-Fos or blood oxygenated level dependent activity, or BOLD) in mammals were included in the systematic review (i.e., 42 studies). Due to lack of methodological instruments, absence of precise standardized coordinate systems, the wide range of experimental procedures, and the diversity of regional anatomy in different species, we were not able to conduct the same rigorous meta-analysis in animals as in humans.

We looked at the following metabolic indexes of non-human animal brain activity: immediate early gene activation (e.g., cFos or Fos-like expression), BOLD activity in fMRI, $\left[{ }^{14} \mathrm{C}\right]-2$ deoxyglucose, and $\left[{ }^{14} \mathrm{C}\right]$-iodoantipyrine. Each of these indexes has previously been related to neural activity and/or metabolism. Considering the broad spectrum of animal models of aversion-related behavior (e.g., footshock exposure, conditioned taste aversion etc.), we looked at all those data that report clear effects in brain activity between control animals and those exposed to non-painful aversive stimuli.

\section{Inclusion and exclusion criteria}

As in humans, our main goal was to investigate the basic neural correlates of aversion. Therefore, we aimed to include only those studies which investigated changes in brain metabolism (e.g., increases in immediate early genes, such as c-Fos, or changes in BOLD activity) related to the mere passive presentation of stimuli (e.g., mild footshock, predatory odor, aversive taste), and not directly related to any behavioral task which might be involved. This is important to note given that many animal studies (including many of those noted here) involve the measurement of a behavioral variable (e.g., avoidance of a stimulus as a reflection of its aversive properties). However, the present studies were chosen for their careful controlling of such behavioral variables and their general focus on brain areas associated with the processing of aversive stimuli. Although an explicit analysis on sensory modality was not undertaken in animals (due to too few studies in each

${ }^{2}$ http://www.columbia.edu/cu/psychology/tor/ 
domain), the available studies were informally compared for brain activations across modalities and compared to the meta-analytic results noted in humans.

Similar to human studies, many animal studies have been excluded for their use of complex behavioral tasks, a focus on social aversion factors, or those focused mainly on memory- or learning-related mechanisms as opposed to basic aversion-related processing. Studies focused on biological/molecular changes or manipulations (e.g., locally injected drugs) related specifically to neurochemicals (which have many known functions throughout the nervous system; e.g., neurotransmitters such as dopamine and GABA), were also excluded in the present study - although the authors acknowledge that future such analyses may prove helpful. In addition, studies involving adolescent animals, chronic exposure to aversive stimuli (as considered in relation to the paradigm under investigation), and exposure to drugs of abuse and drugs which have a known direct effect on aversion- or reward-related brain circuitry, were excluded (although non-drug-exposed controls were included where appropriate). This was done in order to avoid confounding issues related to neurodevelopment and drug interactions and/or drug-induced changes in brain structure or function unrelated to the acute aversive treatment. Studies using electrical/chemical lesions or other irreversible alterations (e.g., the use of knock-out or transgenic rodents or animals bred for psychiatric disorder-related phenotypes) were also excluded for clarity.

These inclusion and exclusion criteria resulted in the selection of almost exclusively studies involving rodents, except for a single study involving macaques (Hoffman et al., 2007). While only one non-human primate study met the strict criteria for inclusion, we have included some primate studies in the discussion section involving electrophysiological techniques or targeted lesions (e.g., Morrison and Salzman, 2009; Machado et al., 2010) in an attempt to better bridge the gap between animals and humans. Nonetheless, while we recognize the limitations of this approach (discussed below), we believe that it is the best available approach at present.

In order to compare aversion-related activity across the human and animal data, we listed the respective regions for both species and checked for hyper- and hypo-activity. As few studies in any domain reported hypoactivity, these are not discussed in detail here. Although a detailed comparison of commonly activated regions in both humans and animals would be informative, spatial limitations in human imaging techniques, and the absence of a clear human-to-non-human-mammal brain atlas, make this difficult beyond the descriptive level. Any comparison between human and animal data raises the question of homology of brain regions. Since they show analogous anatomy and are described by similar names, analysis of subcortical regions do not raise the problem of homology (Panksepp, 1998). In contrast, the issue of homology becomes more problematic in the case of cortical regions that show both anatomical and terminological differences between humans and animals. Nonetheless, even areas which may be considered largely "higher-order" or evolutionarily more recent, such as the prefrontal cortex, may show strong structural and functional homologies between primates and other mammals, such as rodents (Heidbreder and Groenewegen, 2003; Dalley et al., 2004). Concerning cortical regions, we relied on criteria of homology as established by recent authors (Ongur and Price, 2000; Shumake and Gonzalez-Lima, 2003; Vertes, 2006).

\section{RESULTS}

\section{AVERSION-RELATED BRAIN ACTIVATION IN HUMANS}

Meta-analysis results indicated the activation of core aversive brain circuitry involving the amygdala (Amyg), AI, ACC, ventrolateral orbitofrontal cortex (VLOFC), hippocampus (Hipp), and parahippocampal gyrus (Parahipp), dorsal striatum (DS), rostral temporal gyri (RTG), and thalamus (Thal). Significant clusters, extending from regions with peak activations, were also noted in the dorsomedial prefrontal cortex (DMPFC), secondary motor area (SMA), and midbrain (see Figure 1; Table 1, for peak voxel-wise activations and Table 2 for extended clusters). While not a major finding in this study (due to the use of only nine individual contrasts), we also checked for activations which may be specific for the anticipation, as opposed to the reception, of aversive stimuli. In this regard, it is interesting to note that the contrast of anticipation $>$ reception resulted in one small peak cluster of activation $(-16,6,2 ; 10$ voxels) in the putamen of the DS; alternately, the contrast of reception $>$ anticipation resulted in the following peak activations within clusters including: left and right amygdalae, including superior temporal gyrus and hippocampalparahippocampal areas $(-22,-2,-18,605$ voxels; $24,-8,-18$, 97 voxels), right culmen $(42,-46,-26 ; 2$ voxels $)$, right parahippocampal gyrus $(12,0,-20 ; 2$ voxels $)$, right DS $(26,-8,-10 ; 1$ voxel).

As the studies in the meta-analysis investigated the passive reception of aversive stimuli (when compared to non-aversive stimuli; and therefore required little or no action on the part of the subjects), there was no need to control for task-related effects (as related to cognitive task effects). However, the stimuli across studies were presented in various sensory modalities. As such, we attempted to control for unspecific effects associated with distinct sensory modalities (i.e., auditory, tactile, and visual; olfaction and gustation were not investigated due to too few studies) by performing contrasts between the three senses. As the number of visual contrasts was higher (33) than either tactile (5) or auditory (6), six visual contrasts were chosen (twice) at random and compared to the other modalities.

There were no significant activations noted for the following contrasts: tactile > visual; tactile $>$ auditory; auditory $>$ tactile; auditory $>$ visual; visual $>$ auditory. Alternately, the contrast visual $>$ tactile resulted in activation of the left amygdala $(-20$, $-6,-16 ; 110$ voxels; results not shown).

\section{AVERSION-RELATED BRAIN ACTIVATION IN NON-HUMAN ANIMALS}

Animal studies assessing brain activity in response to non-painful aversive stimuli implicated all of the same regions shown in humans (see Table 3). In addition, subcortical areas such as the BNST, habenula (Hab), hypothalamus (Hyp), nucleus of the solitary tract (NTS), NAc, PAG, parabrachial nucleus (PBN), and septal nuclei were also noted. For individual study details and inter-study comparisons, see Table 4.

Similar to the human analysis, brain activations resulting specifically from aversive stimuli in each sensory modality were noted in studies across animals. However, in comparison to human 

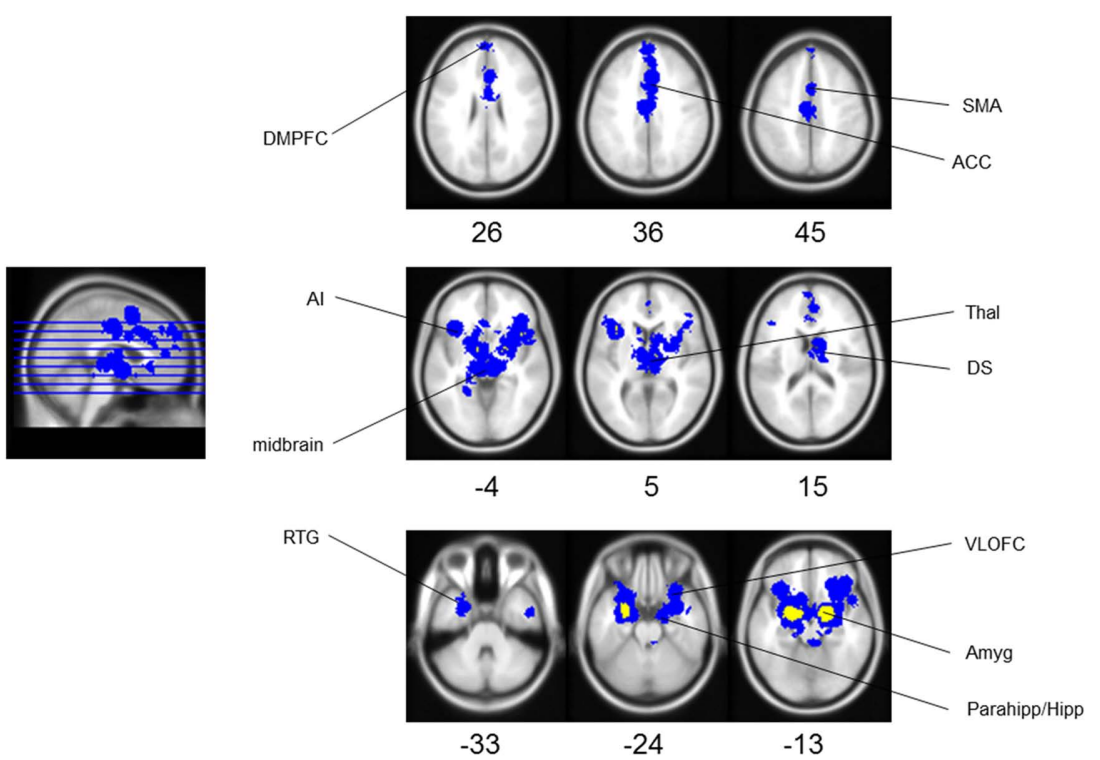

FIGURE 1 | Aversion network in humans. Results of meta-analysis for human aversion-related studies. Yellow represents peak voxels in a local neighborhood, blue represents significant extended clusters. All results are family wise error rate whole-brain corrected at $p<0.05$. The numbers below each axial section represent the $Z$ coordinate. Note that each area is noted only once unilaterally for clarity. See Tables $\mathbf{1}$ and $\mathbf{2}$ for related coordinates and Figure $\mathbf{2}$ for an illustrated summary. Abbreviation: ACC, anterior cingulate cortex; Al, anterior insula; Amyg, amygdala; DMPFC, dorsomedial prefrontal cortex; DS, dorsal striatum; Parahipp/Hipp, parahippocampus/hippocampus; RTG, rostral temporal gyri; SMA, secondary motor cortex; Thal, thalamus; VLOFC, ventrolateral orbitofrontal cortex.

Table 1 | Aversion network in humans - peak voxels.

\begin{tabular}{rrrrrll}
\hline Cluster & & MNI & & $\begin{array}{l}\text { Number of peak voxels } \\
\text { (within clusters }>\mathbf{1 0} \text { voxels) }\end{array}$ & Region \\
\cline { 2 - 4 } & \multicolumn{1}{c}{$\boldsymbol{X}$} & $\boldsymbol{Y}$ & $\boldsymbol{Z}$ & & BA \\
\hline 1 & -22 & -2 & -18 & 526 & Left amygdala, RTG, and hippocampus-parahippocampus \\
2 & -24 & 10 & -28 & 1 & Rostral temporal gyri \\
3 & 20 & -4 & -14 & 386 & Right amygdala, RTG, and hippocampus-parahippocampus \\
4 & -22 & 18 & -20 & 7 & Inferior prefrontal gyrus (OFC) \\
5 & -26 & 18 & -16 & 2 & Inferior frontal gyrus \\
6 & -10 & 4 & -14 & 1 & Parahippocampal gyrus \\
7 & 42 & 16 & -12 & 2 & Inferior frontal gyrus \\
8 & 40 & 16 & -4 & 4 & Inferior prefrontal gyrus (OFC) \\
9 & 44 & 16 & -4 & 1 & Inferior prefrontal gyrus (OFC) \\
10 & -36 & 20 & 4 & 27 & Left anterior insula \\
11 & 30 & 10 & 0 & 1 & Right dorsal striatum (DS) \\
12 & -40 & 16 & 4 & 1 & Left anterior insula \\
13 & 10 & -10 & 6 & 2 & Thalamus \\
14 & 10 & -12 & 10 & 1 & Thalamus \\
\hline
\end{tabular}

Results of MKDA analysis: Peak voxel-wise activations; see Figure 1 for associated activations.

All results are family wise error rate whole-brain corrected at $p<0.05$.

studies, the majority of animal studies (done mostly in rodents) use gustatory or olfactory aversive stimuli. Despite this difference, and similar to the meta-analysis results, there are no areas overlapping with humans which can clearly be identified as modality specific (see Table 4).

\section{CONVERGENCE BETWEEN HUMAN AND ANIMAL DATA}

Comparing the regions found in the human meta-analysis (see Figure 1; Tables 1 and 2) to those found in the systematic animal review (see Tables 3 and 4), a clear overlap of aversion-related brain areas was noted. These areas have been summarized and 
Table 2 | Aversion network in humans - clusters.

\begin{tabular}{|c|c|c|c|c|c|c|}
\hline \multirow[t]{2}{*}{ Cluster } & \multicolumn{3}{|c|}{ MNI } & \multirow{2}{*}{$\begin{array}{l}\text { Size of } \\
\text { clusters }\end{array}$} & \multirow[t]{2}{*}{ Region } & \multirow[t]{2}{*}{ BA } \\
\hline & $x$ & $\boldsymbol{Y}$ & $Z$ & & & \\
\hline 1 & -28 & 6 & -28 & 752 & Left amygdala/left RTG & \\
\hline 2 & 48 & 0 & -30 & 203 & $\begin{array}{l}\text { Right middle temporal } \\
\text { gyrus }\end{array}$ & \\
\hline 3 & 32 & 22 & -18 & 1089 & $\begin{array}{l}\text { Right inferior } \\
\text { prefrontal gyrus (OFC) }\end{array}$ & \\
\hline 4 & 6 & -34 & -16 & 177 & Midbrain (area of PAG) & \\
\hline 5 & -20 & -44 & -6 & 229 & $\begin{array}{l}\text { Left parahippocampal } \\
\text { gyrus }\end{array}$ & \\
\hline 6 & -14 & 2 & -12 & 2276 & $\begin{array}{l}\text { Left hippocampus- } \\
\text { parahippocampal } \\
\text { gyrus }\end{array}$ & \\
\hline 7 & 28 & -6 & -14 & 1486 & Right amygdala & \\
\hline 8 & 38 & 16 & -4 & 1510 & $\begin{array}{l}\text { Right inferior } \\
\text { prefrontal gyrus (OFC) }\end{array}$ & 47 \\
\hline 9 & -34 & 20 & -6 & 1752 & $\begin{array}{l}\text { Left inferior frontal } \\
\text { gyrus }\end{array}$ & \\
\hline 10 & 10 & -24 & 0 & 578 & Thalamus & \\
\hline 11 & -4 & -16 & 0 & 1603 & Thalamus & \\
\hline 12 & 14 & 4 & 8 & 1367 & Dorsal striatum & \\
\hline 13 & 44 & 34 & 0 & 350 & $\begin{array}{l}\text { Right inferior frontal } \\
\text { gyrus }\end{array}$ & \\
\hline 14 & 4 & 24 & 30 & 1084 & $\mathrm{ACC}$ & 32 \\
\hline 15 & 0 & 52 & 32 & 784 & DMPFC & \\
\hline 16 & -2 & -10 & 38 & 1000 & midACC & 24 \\
\hline 17 & 0 & 8 & 54 & 516 & SMA & \\
\hline
\end{tabular}

Results of MKDA analysis: cluster-wise activations; see Figure $\mathbf{1}$ for associated activations.

Contiguous voxels (clusters) significant at $p<0.001$ uncorrected and family wise error rate whole-brain corrected at $p<0.05$.

illustrated in Figure 2 as dark blue brain regions. Additional subcortical regions, identified only in the systematic animal review (although some individual human studies may have also noted them), are identified as light beige brain regions. Furthermore, it is interesting to point out that some areas (i.e., amygdala, insula, prefrontal cortex - including regions of the ACC and orbitofrontal cortices) appeared to show particularly robust activations across both the human and animal analyses.

\section{DISCUSSION}

The present work aimed to clearly identify a network of brain regions involved in the processing of aversive stimuli using a crossspecies translational approach. A comparison was made between studies investigating the passive reception of aversive stimuli in humans (using a meta-analysis; see Figure 1; Tables 1 and 2) and non-human animals (using a systematic review; see Tables 3 and 4).

This translational analysis has identified a core cross-species aversion-related network of brain regions which include cortical (i.e., ACC, AI, DMPFC, RTG, SMA, and VLOFC) and subcortical
Table 3 | Major brain activations in 42 aversion non-human animal studies using brain metabolites (e.g., c-Fos) or neuroimaging.

Rank order: Aversion (42 studies)

\begin{tabular}{lll}
\hline Area & $\begin{array}{l}\text { Studies reporting } \\
\text { activation }\end{array}$ & $\begin{array}{l}\text { Percentage of studies } \\
\text { reporting activation }\end{array}$ \\
\hline Amyg & 32 & 76 \\
Thal & 13 & 30 \\
Hyp & 12 & 29 \\
NTS & 10 & 24 \\
Parahipp/Hipp & 9 & 21 \\
PBN & 8 & 19 \\
PAG & 8 & 19 \\
Ins & 7 & 17 \\
PFC (PL, IL)/OFC & 7 & 17 \\
BNST & 5 & 12 \\
NAc & 5 & 12 \\
Septal & 3 & 7 \\
ACC, DR, DS, LC & 2 Each \\
Motor, habenula, VTA & 1 Each & 5 \\
\end{tabular}

Results are ordered by the number of studies reporting specific activations; percent of studies reporting activations is used for comparative illustration only. Activity reported here appears to be largely independent of sensory modality. For individual study details and inter-study comparisons, see Table 4. See abbreviations list and/or Figures $\mathbf{1}$ and $\mathbf{2}$.

(i.e., Amyg, DS, Hipp, Parahipp, Thal, and midbrain) areas (see Figure 2 for an illustrative summary and Evidence for a Common Core Aversion-Related Network below for more in-depth discussion; also see abbreviations list for area identification). We have termed these regions "core" aversion-related regions as they were collectively identified in the human meta-analysis and, in parallel, confirmed through a review of animal studies. However, it is possible that other regions (i.e., BNST, Hyp, Hab, NAc, NTS, PAG, PBN, and septal nuclei), identified primarily in animals, may also be activated consistently in response to aversive stimuli in humans (and thus be part of the core network, but may be underreported in imaging studies due to technical limitations), and have therefore been indicated (in light beige) in Figure 2. The involvement of some areas (i.e., amygdala, insula, prefrontal cortex) appeared to be a particularly robust finding across both animals and humans. In addition, it was found that this aversion-related processing does not appear to be dependent on the sensory modality in which the aversive stimulus is presented. These data strongly suggest the involvement of these subcortical-cortical regions in aversionrelated processing across species; this activity remains sensory modality independent, thus further supporting the existence of a core neural network mediating aversion.

\section{AVERSIVE STIMULI ACTIVATE A CORE NETWORK IN HUMANS}

The first aim was to identify brain regions associated with the processing of aversive stimuli in humans. These results revealed activations (Figure 1; Tables 1 and 2) which included: Amyg, ACC, VLOFC, DMPFC, secondary motor cortex, Hipp/parahipp, DS, RTG, Thal, and midbrain. These are in accordance with other 


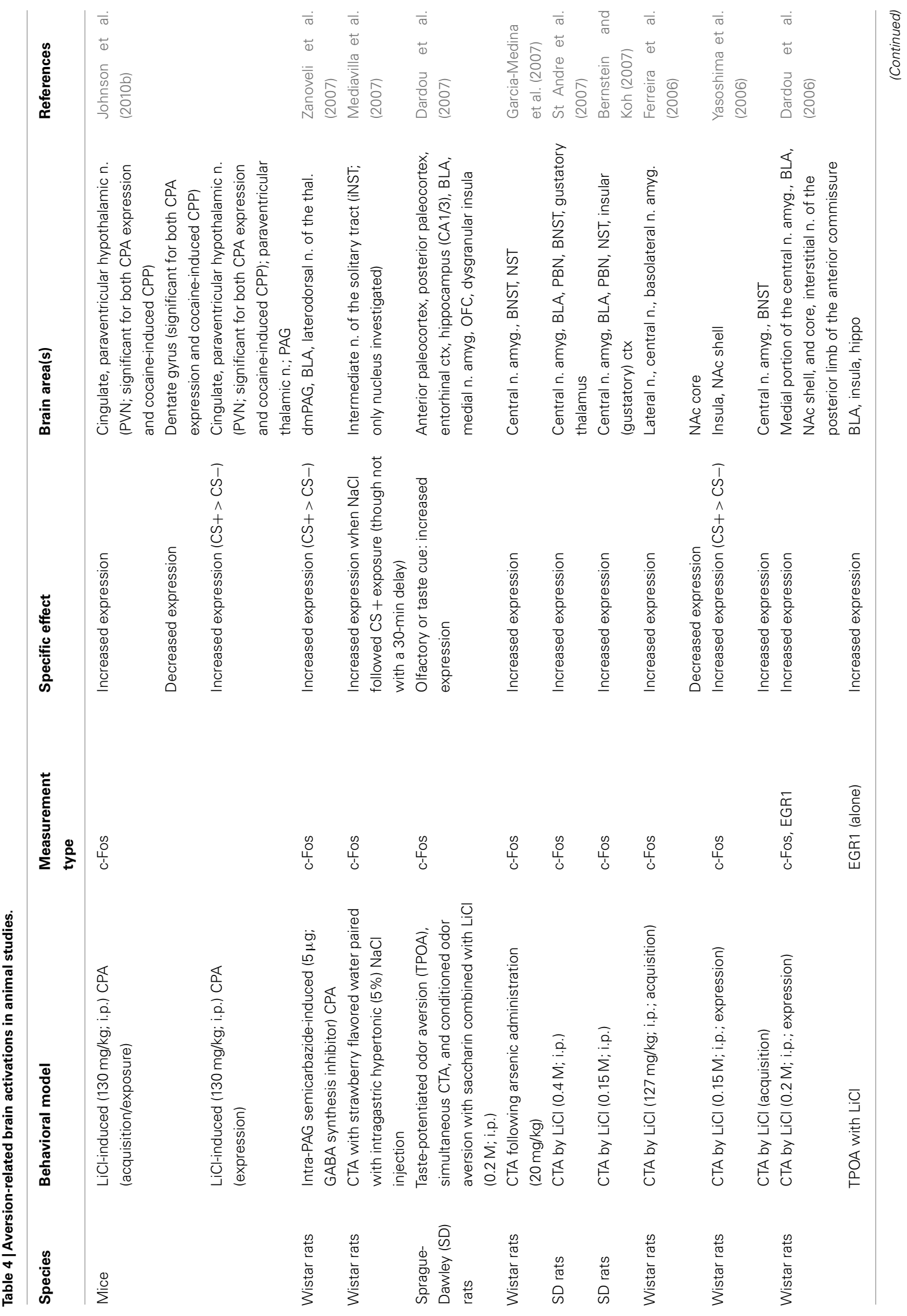




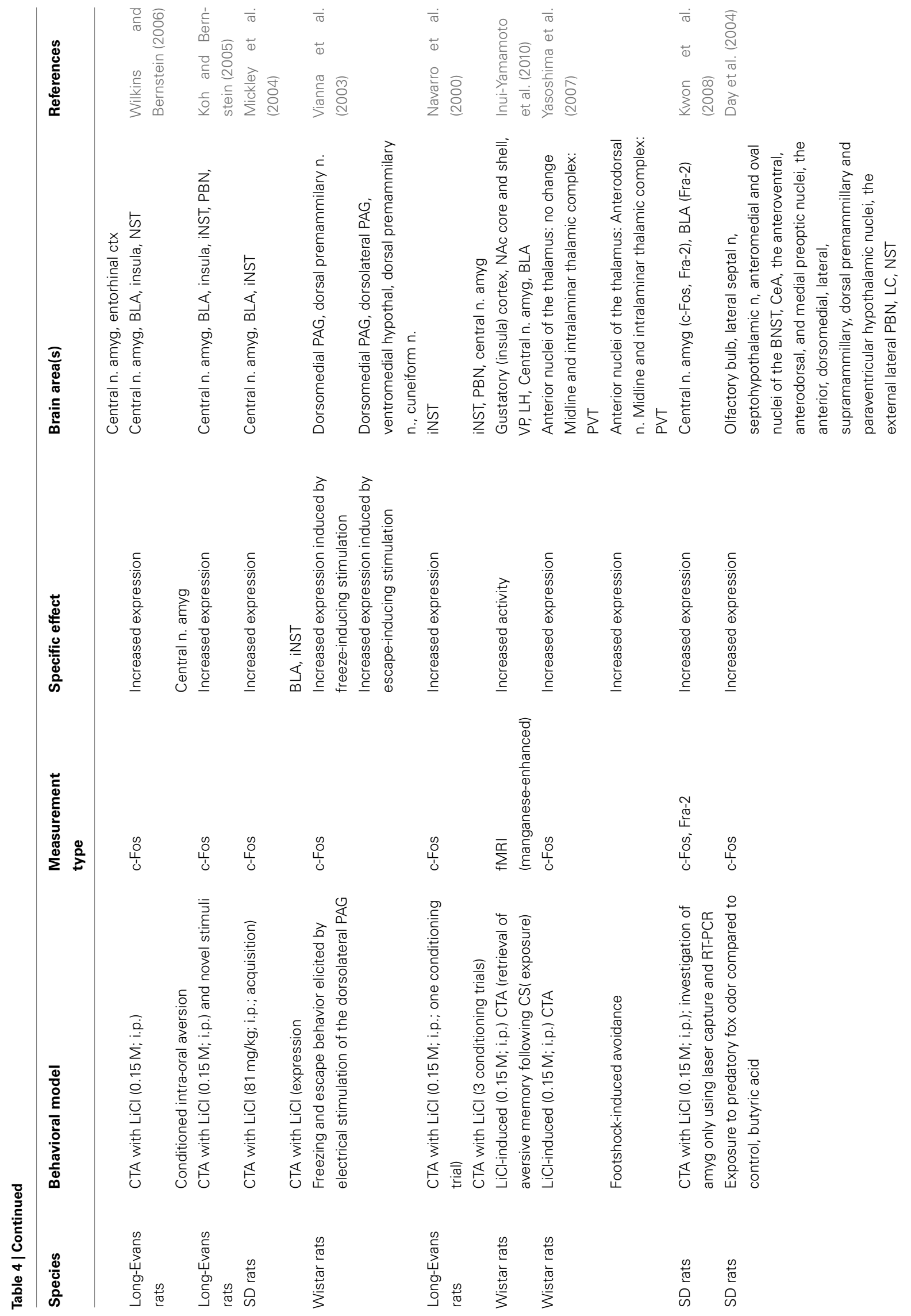




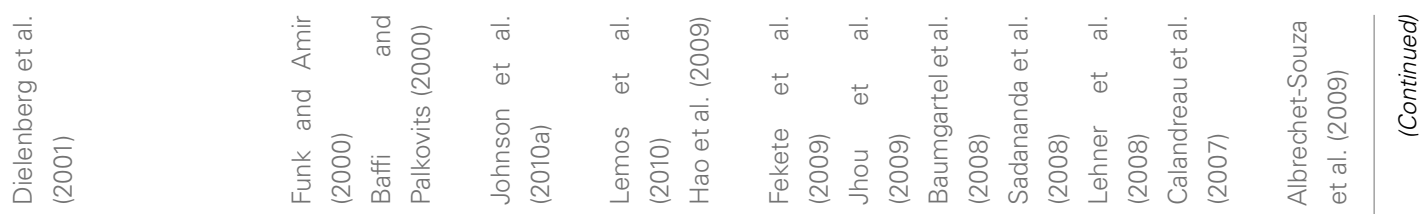

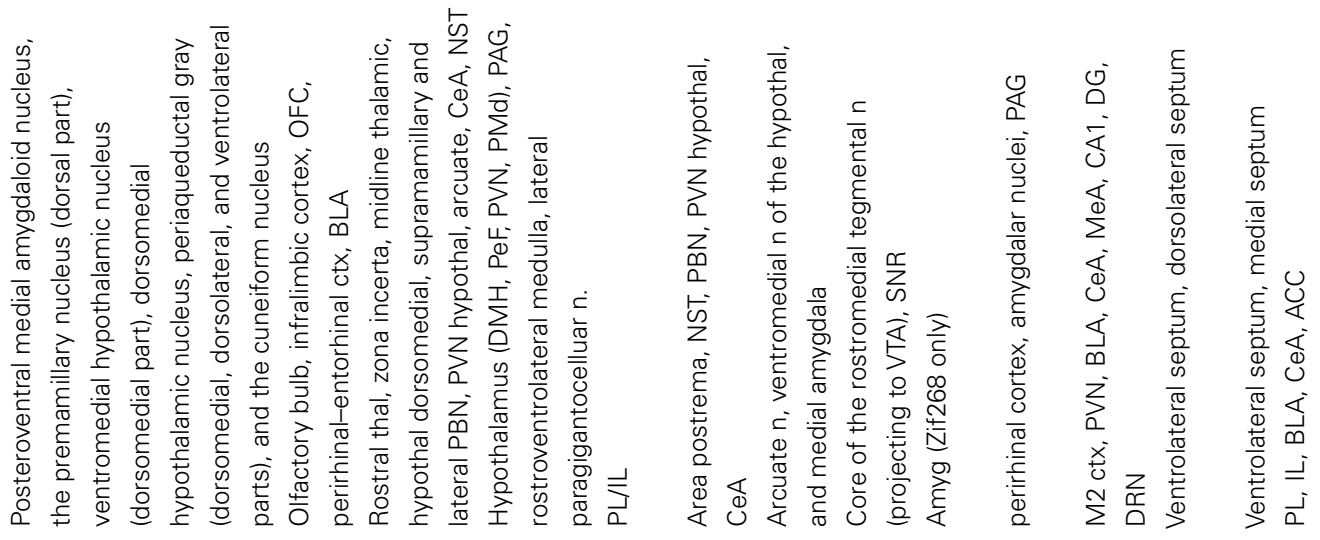

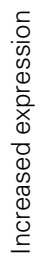

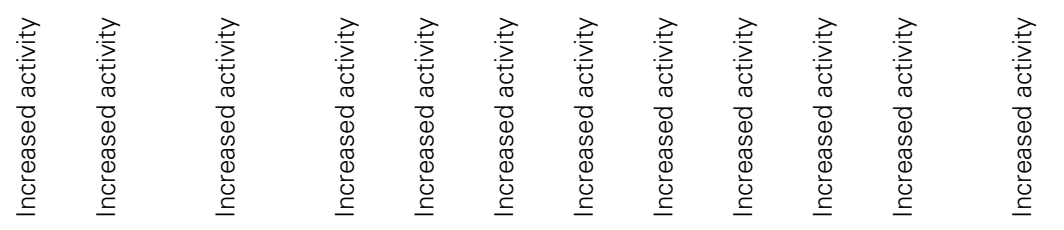

0
0
1
0

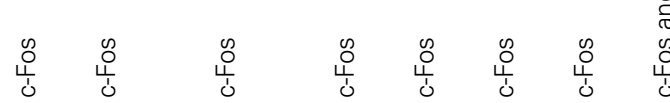

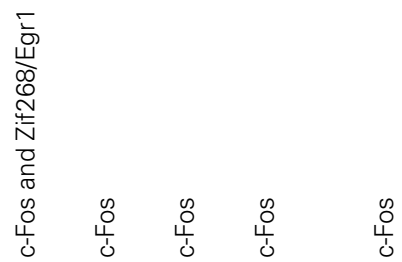

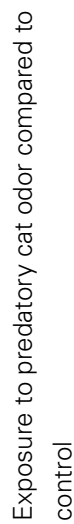
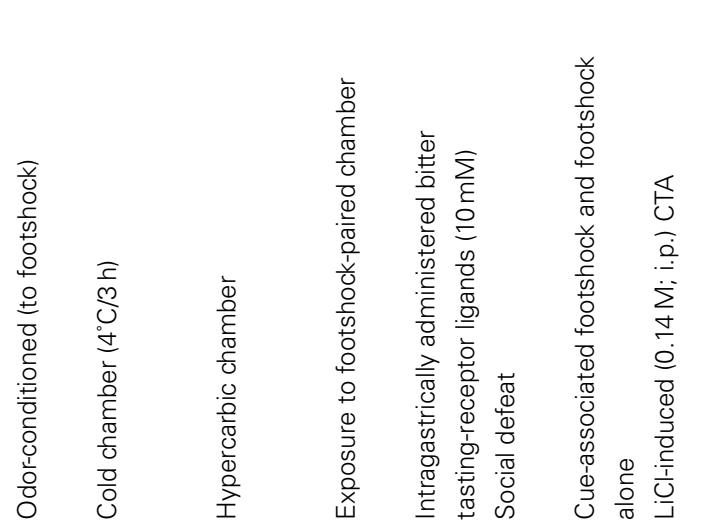

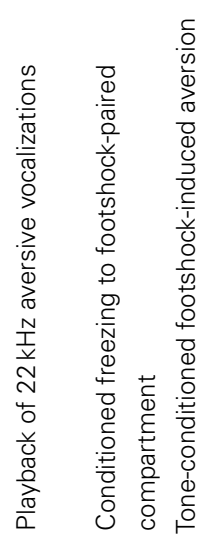

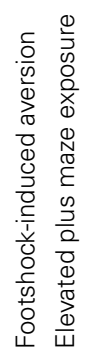

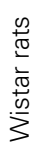

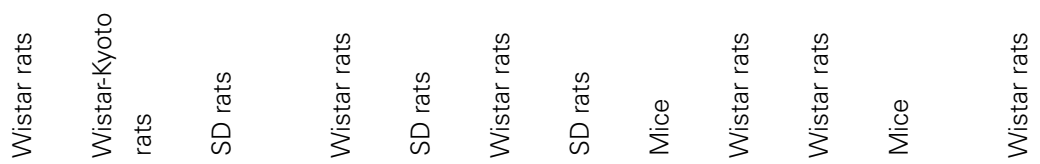




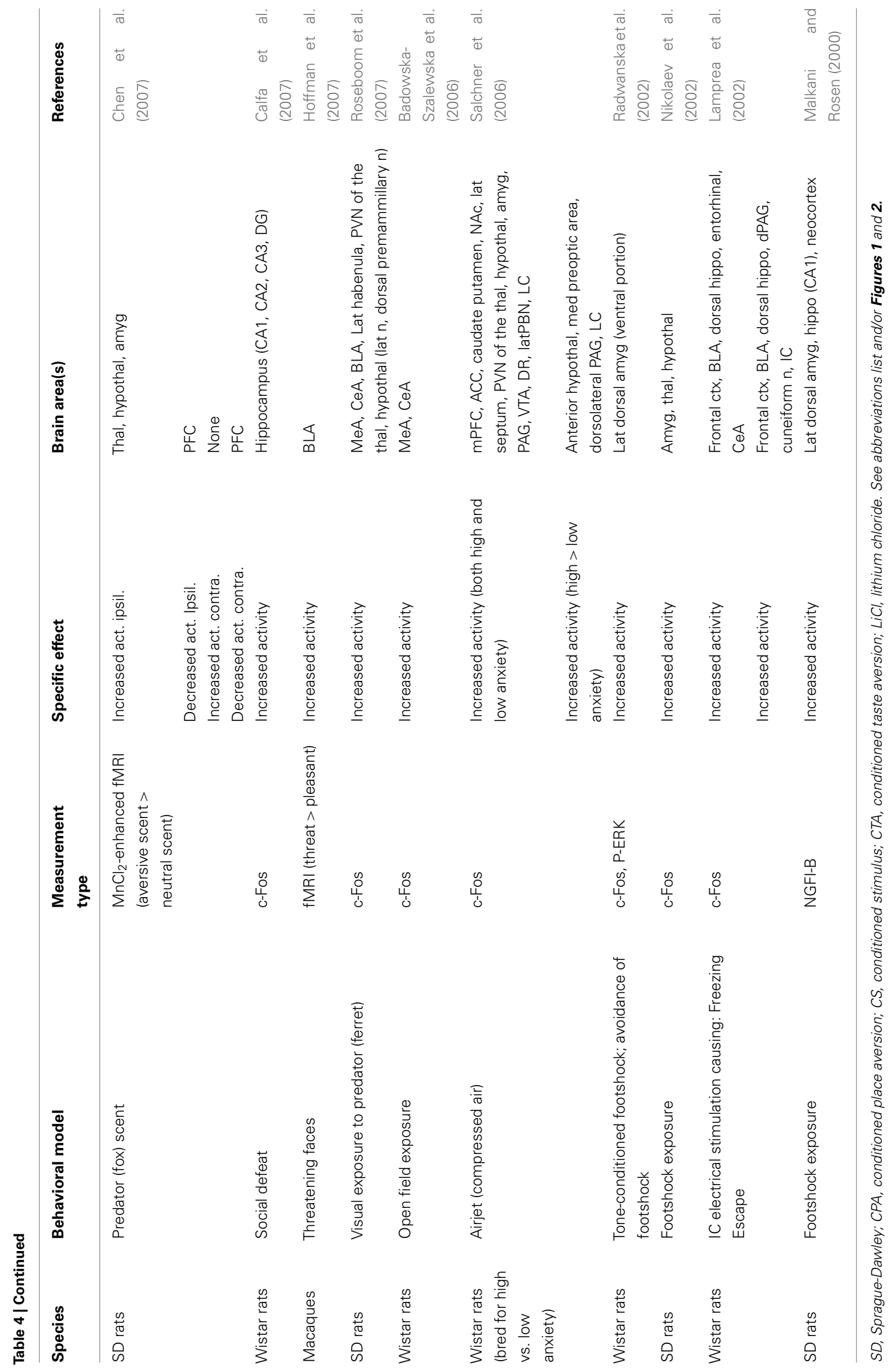




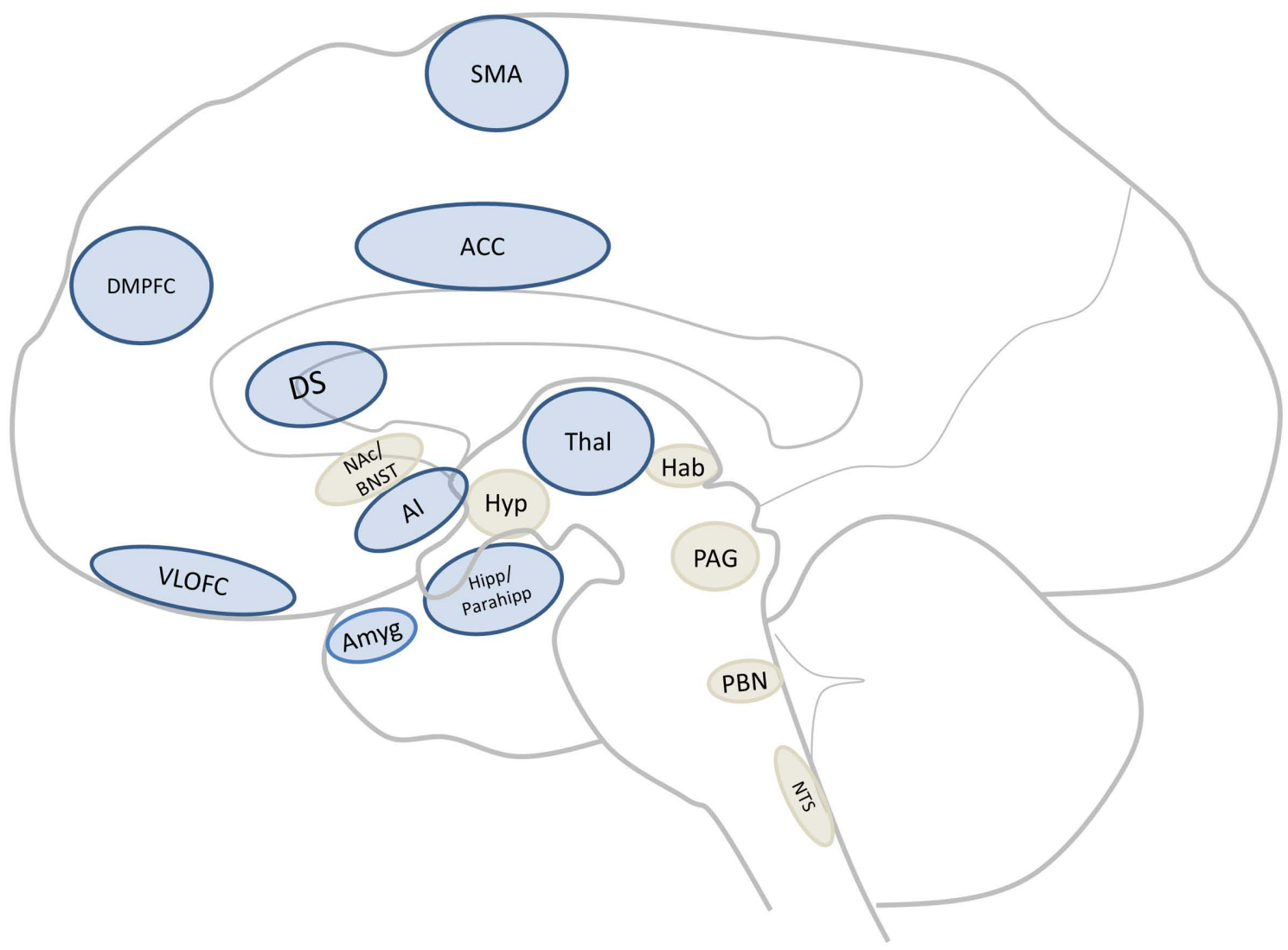

FIGURE 2 | Core aversion-related circuitry. Sagittal section of a human brain illustrating core areas consistent with all data (dark blue; for abbreviations see Figure $\mathbf{1}$ or abbreviations list) as well as those implicated mainly in non-human animal studies (light beige) but which may be core areas across mammals. Abbreviation: BNST, bed nucleus of the stria terminalis; Hab, habenula; Hyp, hypothalamus; NAc, nucleus accumbens; NTS, nucleus of the tractus solitarius; PAG, periaqueductal gray; PBN, parabrachial nucleus. human imaging studies, even those associated with identifying areas specific for some aspects of aversion, such as fear (Klucken et al., 2009), threat (Mobbs et al., 2007), and social punishment (Eisenberger et al., 2007). For example, in a review outlining the putative neurobiology of social punishment, Seymour et al. (2007) rely on human and animal studies to outline a set of structures (i.e., prefrontal, orbital frontal, and anterior insular cortices, basal ganglia, amygdala, and PAG) which they suggest mediate the combined cognitive, conditioning-based, and action-based aspects of social punishment. However, the present results go beyond these suggestions by targeting an even more basic neural network related only to aversive stimuli themselves (when compared to nonaversive ones) that remains independent of behavioral expression in a social or non-social context (Figure 1). This is supported by the fact that the present meta-analysis included only those studies using passive stimuli, while social, cognitive, and behavioral variables were excluded. This makes it seem rather unlikely that the similarly identified brain areas would be unique to social punishment. Instead, combined with our results, their suggestions appear to further support the existence of a core aversion-related network and suggest that aversive stimuli are, at least partly, processed in a similar way using similar neurobiological substrates.

\section{AVERSIVE STIMULI ACTIVATE A CORE NETWORK IN ANIMALS}

While the systematic review of animal studies also identified the same regions as in humans, additional subcortical activations were noted predominantly in animals, including the BNST, Hab, Hyp, NTS, NAc, PAG, PBN, and septal nuclei (see Table 3; although for some instances of subcortical involvement in humans see imaging studies by Becerra et al., 2001; Zald and Pardo, 2002; Jensen et al., 2003; Herwig et al., 2007; Levita et al., 2009). It is, however, important to note that while they support the human meta-analysis data, most animal studies investigate targeted brain regions using explicit, a priori determined, hypotheses (as opposed to using a whole-brain approach). Nonetheless, most studies investigated at least 5 brain regions, with only 8 of the 42 studies focusing on 4 or less (Radwanska et al., 2002; Badowska-Szalewska et al., 2006; Calandreau et al., 2007; Calfa et al., 2007; Hoffman et al., 2007; Mediavilla et al., 2007; Yasoshima et al., 2007; Baumgartel et al., 2008; Kwon et al., 2008). Therefore, the summary in Table 3 of the percentage of animal studies noting specific brain activations must be considered illustrative - as these results will reflect both the involvement of each area in aversion-related processing as well as a general interest in the field of studying such areas. Regardless, similar to that in humans, these results are in accordance 
with other animal studies, even those associated with fear (Lim et al., 2009), threat (Day et al., 2004), and social punishment (Nikulina et al., 2008). Unlike the human studies, however, those in animals are better able to identify and characterize subcortical regions associated with aversion-related processing as well as provide more detailed analysis regarding the precise mechanisms involved (e.g., identifying subregional differences and the role of various biochemicals).

For instance, while the hypothalamus is rarely found to be activated during aversion-related processing in the human literature (e.g., Herwig et al., 2007), many studies in animals have identified this area as playing a key role - particularly in orchestrating the autonomic stress responses related to the presentation of aversive stimuli (for a general review, see Smith and Vale, 2006). These studies have even identified subregions and nuclei within the hypothalamus that appear to be particularly involved, such as the paraventricular (e.g., Johnson et al., 2010a,b), ventromedial (e.g., Fekete et al., 2009), and dorsomedial nuclei (e.g., Baffi and Palkovits, 2000). In addition, while some areas in Table 3 were only identified in a few studies (e.g., habenula, ACC), it should be noted that this is likely due to the stringent inclusion/exclusion criteria applied in the present investigation (e.g., the use of passive perception of aversive stimuli; studies involving metabolic indicators or imaging only). For example, the ACC's inclusion here is also supported by a number of studies using painful aversive stimuli which robustly activate the ACC (Lei et al., 2004a,b; Li et al., 2009). Nonetheless, areas such as the habenula were included in Figure 2 as being potentially good candidates (identified in light beige) for the core aversion-related network as emerging data from animal studies in non-human primates (Matsumoto and Hikosaka, 2009a) and rodents (Roseboom et al., 2007) and some studies in humans (Salas et al., 2010), have indicated its involvement in the processing of aversive stimuli.

Although regions such as the amygdala, AI, and areas of the prefrontal cortex show robust activations across both animals and humans (see further discussion below), it remains unclear what role the subcortical areas, identified mainly in the animal studies, play in the core aversion-related network. This is likely due, in part, to the fact that the role of subcortical areas in human imaging studies are largely underestimated as these techniques typically focus on whole-brain analysis and have lower subcortical and subregional resolution (see Logothetis, 2008 for a brief discussion of fMRI capabilities). While some human imaging studies have identified areas such as the PAG and Hyp in regulating and modulating pain processing (e.g., Hsieh et al., 1996; Becerra et al., 2001), these areas are not typically identified in studies using general aversive stimuli. Alternately, many studies in animals have shown that activation of the PAG (e.g., through electrical or chemical activation) induces aversive responses and activations in other aversionrelated brain areas, and even identify subregional differences (i.e., dorsomedial and dorsolateral PAG) as well as activation-level dependent responding (e.g., freezing, escape, or defensive behaviors; Vianna et al., 2003; Zanoveli et al., 2007). To clarify the role of these regions in human aversion-related processing, future studies of aversion should investigate these subcortical regions in greater detail. Additionally, they could include them in hypotheses regarding their interactions with cortical regions known to be a part of the core aversion-related network -particularly given recent evidence of intrinsic functional connectivity between, for example, the PAG and ACC (Kong et al., 2010).

\section{EVIDENCE FOR A COMMON CORE AVERSION-RELATED NETWORK}

Taken together, this translational analysis identified a core crossspecies aversion-related network of cortical and subcortical areas, including the Amyg, ACC, VLOFC, DMPFC, secondary motor cortex, Hipp/parahipp, DS, RTG, Thal, and midbrain (see Figure 2 which identifies these regions in dark blue and the subcortical regions identified mainly in animals, and considered candidates for the network, in light beige). In order to fully appreciate the function of this network, it will likely be necessary to understand the role of each area. Although this is beyond the scope of the present investigation, it is important to briefly note some of this work in order to underscore its complexity. In this regard, it is interesting to note that the strongest findings across both human and animal studies involved the amygdala, AI, and PFC (including the orbitofrontal cortex and ACC; Figure 1; Table 3 ).

Although the precise role of the amygdala is not fully understood, there is good evidence to suggest that it is involved in processing the saliency (Ewbank et al., 2009) and general valuation (Morrison and Salzman, 2010) of emotional stimuli, as well as being involved in aversive learning and anticipation (Buchel et al., 1998; Sarinopoulos et al., 2009). However, it has also been posited as a core integrator of emotion-related sensory information (Ledoux et al., 1990; Murray, 2007) which may be central in mediating aversive-related processing. While bilateral brain activation is common in response to aversive stimuli, the fact that the left amygdala showed greater activity in response to visual stimuli (and during the reception over the anticipation of stimuli) is consistent with the finding that it appears to be more involved in processing stimuli containing explicitly communicated signals (particularly those which have been acquired through language; see Funayama et al., 2001), as opposed to the right amygdala which is involved more in the processing of implicit/masked stimuli (Costafreda et al., 2008). Overall, the involvement of the amygdalae here is consistent with its role in danger/aversion detection and avoidance as is, for instance, seen in primate studies where amygdala lesions impair aversion-related processing (e.g., the consumption of unpleasant foods or the avoidance of predators or unfriendly conspecifics; Machado and Bachevalier, 2006; Machado et al., 2010).

The variety of functional roles is similarly seen in other regions noted in the present study. For instance, the functions of the ACC and orbitofrontal cortex are equally complex in that they are incompletely understood although they appear to be broadly implicated in functions such as error processing (Simons, 2010), reward-related processing (Haber and Knutson, 2010), and adaptive decision making (Walton et al., 2007, 2010). Similar to the amygdala, these areas may also be involved in sensory processing - particularly regarding the emotional representations associated with olfactory and gustatory information (Rolls, 2008). In addition, electrophysiological studies in humans and non-human primates support the involvement of these regions in aversion-related processing as they have found that single cells in these regions respond to aversive stimuli (Kawasaki et al., 2005; Hosokawa 
et al., 2007; Morrison and Salzman, 2009). Finally, the AI is often considered an intero-exteroceptive convergence zone where exteroceptive input, as for instance a potentially aversive stimulus, is compared and matched with the current interoceptive state of the organisms' body (Craig, 2003, 2009; Lovero et al., 2009). While being intuitively plausible that aversion is closely related to interoceptive stimuli and the current state of the body, experimental support remains to be acquired. Nonetheless, a recent metaanalysis on the role of the human insula found a differentiation of four domains (i.e., sensorimotor, cognitive, social-emotional, and olfacto-gustatory) and an overlapping integrative area in the AI (Kurth et al., 2010) - providing some support for the notion that especially the anterior portion of the insula is an integrator of salient stimuli. This is nicely in accordance with our results from the human data that showed especially the AI to be implicated in mediating aversive stimulus-related processing.

The present investigation demonstrated the amygdala, OFC, and $\mathrm{AI}$ as common regions in aversion in both humans and animals. If these regions are indeed core regions of aversion-related processing, one would assume that their activation remains independent of a specific sensory modality. This is so because aversive stimuli can occur in different sensory modalities, for instance visually (e.g., using complex scenes or images), as used predominantly in human studies, or olfactorily or gustatorily as is the case especially in animal studies. In order to rule out sensory modalityspecific effects, we controlled for them in our meta-analysis. As indicated in the Section "Results," the only sensory-specific activation was noted for the contrast visual $>$ tactile, which revealed a greater activation of the left amygdala ( $-20,-6,-16 ; 110$ voxels). However, this was a relatively small portion of the total activation, and all of the evidence in both humans and animals suggests that the amygdala is involved in processing from all modalities. That aversion-related activations were found to not be specific for sensory modality, while visually (and, though not contrasted here, gustatory and olfactory) aversive stimuli appear to result in somewhat greater activations in the amygdala, is consistent with the literature (Markowitsch, 1998; Costafreda et al., 2008; Mouraux et al., 2011). These results suggest that while sensory-specific regions are, of course, involved in processing stimuli based on their modal origin (e.g., sounds are initially processed in the auditory cortex and inferior colliculi), activation of the core aversion network is largely sensory-independent.

However, there are a few important caveats to note. While there may indeed be a common cross-species neural network for basic aversion-related processing, given the differential reliance on sensory systems across species (e.g., humans rely more heavily on visual information, while rodents rely more heavily on olfactory cues from the environment), the present study cannot comment on the impact of likely species-specific responses to aversive stimuli from the different senses. The specific impact, for instance, of aversive gustatory or olfactory stimuli in humans could have been explored more thoroughly had studies investigating the disgust response been included in the present study (these were left out, as described above, in an attempt to limit potential confounds related to ambiguous and/or higher-order processing such as the response to physical contaminants). Nonetheless, studies included in the meta-analysis which used these sensory stimuli (e.g., Rolls et al., 2003; Grabenhorst et al., 2007), and other studies using cross-modal stimuli (e.g., including olfactory cues in the context of disgust; Seubert et al., 2010a,b), showed activations consistent with a common aversion-related network. Finally, one should be careful not to characterize a whole region as sensory-independent with regard to aversive-related processing. Only some subregions or subpopulation of neurons within a given region may be sensoryindependent while others may mediate sensory-specific effects related to other types of processing, for example those pertaining to reward-related effects. Our present results cannot make any contribution in this direction; however, these results do define those regions that could be targeted in future studies combining single cell recordings and human imaging studies on aversion.

In addition to sensory modality-specific effects, we also ruled out possible behavioral and cognitive confounding effects. This was accomplished by including only human and animal studies which focused on the passive reception of stimuli, where aversive and non-aversive stimuli had to be merely perceived but not acted upon. Our results of a common aversion-related core network must thus reflect the neural processing of aversive stimuli when compared to non-aversive ones rather than some unspecific task-related effects associated with the presentation of the stimuli. We are aware however that despite our careful selection of studies, we are not completely able to rule out task-related effects since even during passive perception some implicit task-related effects may occur. For instance, implicit judgment or attention effects may be greater in aversive (compared to non-aversive) stimulus processing. Future studies focusing on the interaction between aversive (vs. non-aversive) stimuli and task-related effects (like judgment, attention or anticipation) may therefore need to be conducted. Additionally, the degree of aversion from moderate to severe should also be considered in future, as should the comparison to pain-related activations. Nonetheless, it is important to point out that a recent set of experiments by Mouraux et al. (2011) which investigated brain activations in fMRI to pain- vs. non-pain stimuli using visual and auditory stimuli, revealed results which are well in line with those described here, both in terms of the network involved as well as indicating modality-independence.

Taken together, these results demonstrate that this core aversion-related network is activated independent of sensory modality and is not related explicitly to cognitive or behavioral effects. In addition, while no single brain area is responsible for the processing of aversive stimuli, there may be at least some differentiation at the subregional (e.g., rostrocaudal/anteroposterior gradations) and/or neuronal level. Regardless, these results raise many questions and leave open numerous possibilities for future studies, including: Is this aversion-related network specific for aversive stimuli? How does the network differentially encode the anticipation and reception of aversive stimuli? And what neurochemical mechanisms are involved?

\section{FUTURE DIRECTIONS AND LIMITATIONS}

Is this aversion-related network specific for the processing of aversive stimuli? Given the fact that the observed core aversion-related network appears to remain independent of sensory, cognitive, and behavioral processing, one may raise the question of exactly what kind of processing is mediated by this network. Although we 
aimed to remove any potential cognitive effects by focusing on studies employing the use of passive aversive stimuli, we cannot completely eliminate the possible impact of "top-down" processes (such as cognitive reappraisal). In particular, as event-related fMRI designs generally use the repetition of stimuli across many trials, subjects may be consciously or automatically/unconsciously using coping strategies to help control their emotional responses to the unpleasant stimuli. Although we suspect that each of the regions presently identified are involved in basic aversion-related processing, it is probable that some are also particularly involved in higher-order cognitive processing as well. As such, future studies should continue to investigate the impact of stimulus anticipation and trial repetition, especially as a few studies have already suggested differential activities within regions such as the amygdala and areas of the prefrontal cortex (Wright et al., 2008; Kanske et al., 2011). In addition, these results should be compared directly to those from animal studies employing very similar designs in order to provide comparative translational evidence for the precise role of each network component.

Another suggestion is that this network processes stimulus saliency (i.e., the importance of a stimulus to a particular organism, irrespective of valence), especially given that the amygdala, for instance, is involved in processing the saliency of emotional stimuli (Ewbank et al., 2009). However, although stimulus saliency may be involved in the activation of some areas (e.g., insula, amygdala; Menon and Uddin, 2010), it may not be specific to aversive-related processing. For instance, saliency may also be central in rewardrelated processing in order to help detect potentially valuable, and thus rewarding, stimuli (see for instance Zink et al., 2004; Grabenhorst et al., 2010). Furthermore, this raises the question regarding the relationship between reward and aversion.

Both reward- and aversion-related stimuli are highly salient a fact that might be reflected in the common activation of many brain regions such as the OFC, ACC, and NAc, as noted above. Nonetheless, there are many regions which are currently thought to be selectively or predominantly activated during the presentation of either rewarding or aversive stimuli. For instance, some areas that appear to be more selective for reward include the ventromedial prefrontal cortex, nucleus basalis, ventral pallidum, and dorsal VTA (Tindell et al., 2006; Brischoux et al., 2009; CybulskaKlosowicz et al., 2009; Xue et al., 2009), while those that are more selective for aversion include the amygdala (particularly the central and basolateral nuclei; also underscored in Table 4; however, there are a number of studies in both humans and animals identifying its role in reward, for instance see Holland and Gallagher, 2004), DMPFC, ventral VTA (Brischoux et al., 2009; Machado et al., 2009; Xue et al., 2009). Emerging evidence at the cellular/neurochemical level is showing that, overall, different populations of dopamine cells encode value and salience and do so through differential signaling patterns (Matsumoto and Hikosaka, 2009b; BrombergMartin et al., 2010). However, all salient and highly emotional stimuli tend to include, by definition, value, and valence (i.e., they are rewarding or aversive to some degree). Thus, the fact that they are conceptually tied may be reflected by an inability to completely dissociate them experimentally. Regardless of such concerns, these data suggest that it is most likely that the combined aversion-related activations reported in the present investigation cannot be merely attributed to saliency, although the exact nature of the relationship between saliency, aversion, and reward is still unclear. Future studies and meta-analyses should aim to clarify the similarities and differences between processing related to saliency, aversion, and reward.

One major limitation of the present study in addressing these issues, as noted above, is the fact that brain imaging techniques typically have lower subcortical and subregional resolution. However, consideration of some imaging studies identifying subcortical areas in aversion-related processing (e.g., Jensen et al., 2003; Herwig et al., 2007; Levita et al., 2009) and the inclusion of animal studies in the present investigation have helped to reduce these limitations. Nonetheless, it is clear that at least some areas within the network code for multiple (even apparently opponent) processes (e.g., aversion and reward). For instance, many animal studies (e.g., Hayes et al., 2010; and see Carlezon and Thomas, 2009 for review) and some human work (Levita et al., 2009; see also Leknes and Tracey, 2008) have implicated the NAc as playing a key role in coding for both aversive and rewarding states. In addition, there are numerous cell types with various response characteristics throughout the amygdala, OFC, and ACC which may respond to the presence or anticipation of rewarding, aversive, or both types of stimuli; often in the absence of an obvious topology (Kawasaki et al., 2005; Paton et al., 2006; Morrison and Salzman, 2009; Shabel and Janak, 2009).

Like with reward, there may be subregional and neuronal differentiations which correspond to other processing and/or behavioral aspects of aversion such as fear, anxiety, and pain. While the exclusion of studies looking at these specific aversion-related concepts in the present study have allowed for the control of complex behavioral and cognitive factors, it is nonetheless clear that future investigations should include these studies in comparison to the present core aversion-related network. Although studies from these respective fields have largely implicated the involvement of brain areas which are in general agreement with the present study (for example, see the discussion of work by Seymour et al., 2007 above), these findings should be confirmed in future analyses.

In turn, these open questions lead to another question: How is the anticipation/expectation of aversive stimuli coded by the aversion-related network? To what degree are these processes separate? (For a discussion of the latter question, see Bermpohl et al., 2006) While not a major finding in this study (resulting from only nine available contrasts), anticipation > reception of the aversive stimulus resulted in one small cluster of activation in the DS (-16, 6, 2; 10 voxels), compared to the dominant activation of the amygdalae (particularly the left side) resulting from reception (anticipation (as noted above). Although this result must be considered with caution, this is a potentially interesting finding which should be investigated further as suggestions from other animal (Salchner et al., 2006) and human (Lutcke et al., 2009) studies have identified dorsal striatal activation in anticipation. Another related issue for future studies to consider is the role of temporal coding. For instance, some researchers have shown that we prefer predictable (over unpredictable) aversive outcomes - as reflected behaviorally and by reduced activations in areas of the aversion-related network (Carlsson et al., 2006; Sarinopoulos et al., 2009). 
A related consideration involves the potential role of intrinsic brain activity, or the so-called resting state, on aversion-related processing. Though nearly all of the studies included in the metaanalysis contrasted known aversive stimuli to their neutral equivalent (e.g., aversive vs. neutral pictures), only a few used what could be considered true resting state conditions (e.g., viewing a static image of a fixation-cross; e.g., Liberzon et al., 2002; Phan et al., 2003). As such, it was not possible to investigate the potential impact of different baselines in general and the resting state in particular. As noted above, given recent evidence of intrinsic functional connectivity between, for example, the PAG and ACC (Kong et al., 2010), which appear to be key components of the aversion-related circuit, it is possible that resting state activity is fundamentally involved in aversion-related processing. As such, it is recommended that future studies on aversion aim to include some resting state information in their designs (Northoff et al., 2010).

Finally, future studies (especially in humans) should further investigate the possible neurochemical mechanisms of aversionrelated processing. Glutamate, GABA, dopamine, and serotonin have all been implicated (as have other neurotransmitters), but given the complexity of possible interactions much more work is needed. For instance, numerous animal studies have demonstrated a role for glutamate and GABA (particularly the NMDA and $\mathrm{GABA}_{\mathrm{A}}$ receptors, respectively) in the ACC (Lei et al., 2004a; Wang et al., 2005) and for NMDA receptors in the insula (Ferreira et al., 2005). These findings have been supported by a few studies in humans using magnetic resonance spectroscopy to

Box 1 | Altered aversion processing in psychiatric disorders. Examples of studies that have implicated aversion-related processing as being dysfunctional in some psychiatric disorders.

\section{Psychiatric disorder Evidence of altered aversion-related processing}

Depression

Addiction

Schizophrenia

Anxiety disorders the expectation of positive stimuli.
Borderline personality Few imaging studies have been performed in this group, however, altered aversion-

Compared with healthy controls, patients with major depressive disorder (MDD) show increased activation in the right amygdala, and decreased activations in PAG, ACC, prefrontal cortex to the reception of painful > non-painful stimuli; they also show increased activation in the right anterior insula, dorsal ACC, and right amygdala during the anticipation of painful > non-painful stimuli. Also, recovered patients with a history of MDD showed decreased ventral striatal activity to rewarding stimuli and increased dorsal striatal (i.e., caudate nucleus) activity to aversive stimuli. In addition, anticipation of aversive stimuli in patients with depression results in greater activations within the sublenticular extended dorsal amygdala compared to controls, with no differences in

Although little research has been done specifically regarding aversion-related processing and addiction, there is an abundance of research in both humans and animals regarding how stressful/aversive stimuli and drug-associated cues (which are often reported to be highly aversive) can trigger drug seeking and relapse. For instance, one study by Wheeler et al. (2008) showed that saccharin (a rewarding taste for rats) can become an aversive cue when signaling cocaine availability; the switch in affective state from positive to negative in reflected by the activity of NAc cells. In this context, a recent review highlighted the approach of using extinction learning of these aversive cues in addicts to prevent or attenuate future relapse and craving.

Compared with healthy controls, patients show inappropriately strong ventral striatal activations to neutral stimuli in an aversive learning paradigm. Behaviorally, they also show an inability to properly identify neutral stimuli (reporting them as aversive) which is also consistent with their abnormal autonomic reactivity to these stimuli (e.g., galvanic skin responses). This abnormal aversion-related processing may also be reflected behaviorally by their lack of loss aversion (i.e., the typical behavior of assigning greater value to that which can be lost over that which can be gained). related processing may be involved in the pathophysiology as behaviorally these patients show increased pain thresholds and often engage in self-mutilation. However, one fMRI study by Herpertz et al. (2001) showed increased amygdalae and prefrontal (medial and inferolateral) activation in these patiets compared to controls.

Converging evidence in humans and animals suggests that some anxiety disorders (particularly post-traumatic stress disorder; PTSD) may be related to an inability to inhibit aversion-related signaling. A functional neuroimaging meta-analysis by Etkin and Wager (2007) of PTSD, social phobia, and social anxiety showed that patients in all three groups have hyperactive amygdala and insula function. In addition, patients with PTSD showed hypoactivity in the ACC and ventromedial prefrontal cortex. Neuroendocrinological studies have suggested that the amygdala hyperactivity may be related to hypothalamic-pituitary-adrenal axis dysfunction.
References

Abler et al. (2007), Strigo et al. (2008), McCabe et al. (2009)

Weiss et al. (2001), Wheeler et al. (2008), Kaplan et al. (2010)

Jensen et al. (2008), Tremeau et al. (2008)

Herpertz et al. (2001), Ludascher et al. (2007)

Etkin and Wager (2007), Jovanovic et al. (2010), Norrholm et al. (2010) 
show enhanced ACC (Mullins et al., 2005) and anterior insular (Gussew et al., 2010) glutamate levels following painful stimulation of the hands and feet. Dopamine transmission in the amygdala, NAc, DS, and dorsal ACC (Scott et al., 2006; Menon et al., 2007; Kienast et al., 2008) may also be involved in various aspects of aversion-related processing in humans. Although its role in animals has been studied extensively, it is still unclear precisely how this neurotransmitter mediates aversive signals (e.g., Liu et al., 2008; but see Mirenowicz and Schultz, 1996). Serotonin may also play an important role in aversive processing, for example by modulating/opposing reward-related behaviors (e.g., Hayes et al., 2009), although there is still much discussion about what mechanisms might be involved (Jhou, 2005; Dayan and Huys, 2009; Tops et al., 2009) - particularly as one recent human fMRI study showed that increased serotonergic transmission resulted in blunted aversion- and reward-related processing (McCabe et al., 2010).

\section{CONCLUSION}

To our knowledge, this is the first report using a systematic translational approach investigating aversion-related processing in humans and other animals. It was demonstrated that humans and

\section{REFERENCES}

Abler, B., Erk, S., Herwig, U., and Walter, H. (2007). Anticipation of aversive stimuli activates extended amygdala in unipolar depression. J. Psychiatr. Res. 41, 511-522.

Albrechet-Souza, L., Borelli, K. G., Carvalho, M. C., and Brandao, M. L. (2009). The anterior cingulate cortex is a target structure for the anxiolytic-like effects of benzodiazepines assessed by repeated exposure to the elevated plus maze and Fos immunoreactivity. Neuroscience 164, 387-397.

Alcaro, A., Panksepp, J., Witczak, J., Hayes, D. J., and Northoff, G. (2010). Is subcortical-cortical midline activity in depression mediated by glutamate and GABA? A crossspecies translational approach. Neurosci. Biobehav. Rev. 34, 592-605.

Anderson, A. K., Christoff, K., Panitz, D., De Rosa, E., and Gabrieli, J. D. (2003). Neural correlates of the automatic processing of threat facial signals. J. Neurosci. 23, 5627-5633.

Ardiel, E. L., and Rankin, C. H. (2010). An elegant mind: learning and memory in Caenorhabditis elegans. Learn. Mem. 17, 191-201.

Bach, D. R., Weiskopf, N., and Dolan, R. J. (2011). A stable sparse fear memory trace in human amygdala. J. Neurosci. 31, 9383-9389.

Badowska-Szalewska, E., Ludkiewicz, B., Domaradzka-Pytel, B., Dziewiatkowski, J., Spodnik, J. H., and Morys, J. (2006). The immunoreactivity of c-Fos, NGF and its receptor TrkA after openfield exposure in the central and medial nuclei of the rat amygdala. Folia Morphol. (Warsz) 65, 145-151. Baffi, J. S., and Palkovits, M. (2000). Fine topography of brain areas activated by cold stress. A fos immunohistochemical study in rats. Neuroendocrinology 72, 102-113.

Baumgartel, K., Genoux, D., Welzl, H., Tweedie-Cullen, R. Y., Koshibu, K., Livingstone-Zatchej, M., Mamie, C., and Mansuy, I. M. (2008). Control of the establishment of aversive memory by calcineurin and Zif268. Nat. Neurosci. 11, 572-578.

Becerra, L., Breiter, H. C., Wise, R., Gonzalez, R. G., and Borsook, D. (2001). Reward circuitry activation by noxious thermal stimuli. Neuron 32, 927-946.

Bermpohl, F., Pascual-Leone, A., Amedi, A., Merabet, L. B., Fregni, F., Gaab, N., Alsop, D., Schlaug, G., and Northoff, G. (2006). Dissociable networks for the expectancy and perception of emotional stimuli in the human brain. Neuroimage 30, 588-600.

Bernstein, I. L., and Koh, M. T. (2007). Molecular signaling during taste aversion learning. Chem. Senses 32, 99-103.

Brischoux, F., Chakraborty, S., Brierley, D. I., and Ungless, M. A. (2009). Phasic excitation of dopamine neurons in ventral VTA by noxious stimuli. Proc. Natl. Acad. Sci. U.S.A. 106, 4894-4899.

Bromberg-Martin, E. S., Matsumoto, M., and Hikosaka, O. (2010).

animals have a common core aversion-related network, consisting of similar cortical and subcortical regions, and that its activity is largely independent of sensory modality and cognitive (e.g., task-related) effects. The identification of this core network helps to explain the reported overlap of neural substrates noted across aversion-related concepts (e.g., pain, fear, punishment). This perspective, in conjunction with future work to identify the precise subregional and neurochemical mechanisms involved, will contribute to a better understanding of how aversive stimuli are processed in both animals and healthy individuals as well as those subjects with psychiatric disorders (like addiction or depression) displaying dysfunctional aversion processing (see Box 1 for examples).

\section{ACKNOWLEDGMENTS}

The authors would like to thank Niall W. Duncan for his assistance with the MKDA meta-analysis and his critical reading of the manuscript. Georg Northoff holds a Canada Research Chair for Mind, Brain imaging and Neuroethics as well as an EJLB-CIHR Michael Smith Chair in Neurosciences and Mental Health. Dave J. Hayes holds a Postdoctoral Fellowship from the Canadian Institutes of Health Research (CIHR).

Dopamine in motivational control: rewarding, aversive, and alerting. Neuron 68, 816-834.

Buchel, C., Morris, J., Dolan, R. J., and Friston, K. J. (1998). Brain systems mediating aversive conditioning: an event-related fMRI study. Neuron 20, 947-957.

Calandreau, L., Jaffard, R., and Desmedt, A. (2007). Dissociated roles for the lateral and medial septum in elemental and contextual fear conditioning. Learn. Mem. 14, 422-429.

Calfa, G., Bussolino, D., and Molina, V. A. (2007). Involvement of the lateral septum and the ventral hippocampus in the emotional sequelae induced by social defeat: role of glucocorticoid receptors. Behav. Brain Res. 181, 23-34.

Carlezon, W. A. Jr., and Thomas, M. J. (2009). Biological substrates of reward and aversion: a nucleus accumbens activity hypothesis. Neuropharmacology 56(Suppl. 1), 122-132.

Carlsson, K., Andersson, J., Petrovic, P., Petersson, K. M., Ohman, A., and Ingvar, M. (2006). Predictability modulates the affective and sensorydiscriminative neural processing of pain. Neuroimage 32, 1804-1814.

Chakrabarti, B., Bullmore, E., and Baron-Cohen, S. (2006). Empathizing with basic emotions: common and discrete neural substrates. Soc. Neurosci. 1, 364-384.

Chen, W., Tenney, J., Kulkarni, P., and King, J. A. (2007). Imaging unconditioned fear response with manganese-enhanced MRI (MEMRI). Neuroimage 37, 221-229.

Chua, P., Krams, M., Toni, I., Passingham, R., and Dolan, R. (1999). A functional anatomy of anticipatory anxiety. Neuroimage 9, 563-571.

Costafreda, S. G., Brammer, M. J., David, A. S., and Fu, C. H. (2008). Predictors of amygdala activation during the processing of emotional stimuli: a meta-analysis of 385 PET and fMRI studies. Brain Res. Rev. 58, 57-70.

Craig, A. D. (2003). Interoception: the sense of the physiological condition of the body. Curr. Opin. Neurobiol. 13, 500-505.

Craig, A. D. (2009). Emotional moments across time: a possible neural basis for time perception in the anterior insula. Philos. Trans. R. Soc. Lond. B Biol. Sci. 364, 1933-1942.

Cybulska-Klosowicz, A., Zakrzewska, R., and Kossut, M. (2009). Brain activation patterns during classical conditioning with appetitive or aversive UCS. Behav. Brain Res. 204, 102-111.

Dalley, J. W., Cardinal, R. N., and Robbins, T. W. (2004). Prefrontal executive and cognitive functions in rodents: neural and neurochemical substrates. Neurosci. Biobehav. Rev. 28, 771-784.

Dardou, D., Datiche, F., and Cattarelli, M. (2006). Fos and Egrl expression in the rat brain in response to olfactory cue after taste-potentiated odor aversion retrieval. Learn. Mem. 13, 150-160. 
Dardou, D., Datiche, F., and Cattarelli, M. (2007). Does taste or odor activate the same brain networks after retrieval of taste potentiated odor aversion? Neurobiol. Learn. Mem. 88, 186-197.

Day, H. E., Masini, C. V., and Campeau, S. (2004). The pattern of brain cfos mRNA induced by a component of fox odor, 2,5-dihydro-2,4,5trimethylthiazoline (TMT), in rats, suggests both systemic and processive stress characteristics. Brain Res. 1025, 139-151.

Dayan, P., and Huys, Q. J. (2009). Serotonin in affective control. Annu. Rev. Neurosci. 32, 95-126.

Delgado, M. R., Jou, R. L., and Phelps, E. A. (2011). Neural systems underlying aversive conditioning in humans with primary and secondary reinforcers. Front. Neurosci. 5:71. doi: 10.3389/fnins.2011.00071

Dielenberg, R. A., Hunt, G. E., and Mcgregor, I. S. (2001). "When a rat smells a cat": the distribution of Fos immunoreactivity in rat brain following exposure to a predatory odor. Neuroscience 104, 1085-1097.

Eisenberger, N. I., Gable, S. L., and Lieberman, M. D. (2007). Functional magnetic resonance imaging responses relate to differences in real-world social experience. Emotion 7, 745-754

Eisenberger, N. I., Lieberman, M. D., and Williams, K. D. (2003). Does rejection hurt? An FMRI study of social exclusion. Science 302, 290-292.

Etkin, A., and Wager, T. D. (2007). Functional neuroimaging of anxiety: a meta-analysis of emotional processing in PTSD, social anxiety disorder, and specific phobia. Am. J. Psychiatry 164, 1476-1488.

Ewbank, M. P., Barnard, P. J., Croucher, C. J., Ramponi, C., and Calder, A. J. (2009). The amygdala response to images with impact. Soc. Cogn. Affect. Neurosci. 4, 127-133.

Fan, Y., Duncan, N. W., De Greck, M., and Northoff, G. (2010). Is there a core neural network in empathy? An fMRI based quantitative metaanalysis. Neurosci. Biobehav. Rev. 35, 903-911.

Fekete, E. M., Zhao, Y., Li, C., Sabino, V., Vale, W. W., and Zorrilla, E. P. (2009). Social defeat stress activates medial amygdala cells that express type 2 corticotropin-releasing factor receptor mRNA. Neuroscience 162, 5-13.

Ferreira, G., Ferry, B., Meurisse, M., and Levy, F. (2006). Forebrain structures specifically activated by conditioned taste aversion. Behav. Neurosci. 120, 952-962.
Ferreira, G., Miranda, M. I., De La Cruz, V., Rodriguez-Ortiz, C. J., and Bermudez-Rattoni, F. (2005). Basolateral amygdala glutamatergic activation enhances taste aversion through NMDA receptor activation in the insular cortex. Eur. J. Neurosci. 22, 2596-2604.

Funayama, E. S., Grillon, C., Davis, M. and Phelps, E. A. (2001). A double dissociation in the affective modulation of startle in humans: effects of unilateral temporal lobectomy. J. Cogn. Neurosci. 13, 721-729.

Funk, D., and Amir, S. (2000). Enhanced fos expression within the primary olfactory and limbic pathways induced by an aversive conditioned odor stimulus. Neuroscience 98, 403-406.

Garcia-Medina, N. E., JimenezCapdeville, M. E., Ciucci, M., Martinez, L. M., Delgado, J. M., and Horn, C. C. (2007). Conditioned flavor aversion and brain Fos expression following exposure to arsenic. Toxicology 235, 73-82.

Glanzman, D. L. (2005). Associative learning: Hebbian flies. Curr. Biol. 15, R416-R419.

Grabenhorst, F., D'souza, A. A., Parris, B. A., Rolls, E. T., and Passingham, R. E. (2010). A common neural scale for the subjective pleasantness of different primary rewards. Neuroimage 51, 1265-1274.

Grabenhorst, F., Rolls, E. T., Margot, C., Da Silva, M. A., and Velazco, M. I. (2007). How pleasant and unpleasant stimuli combine in different brain regions: odor mixtures. J. Neurosci. 27, 13532-13540.

Gussew, A., Rzanny, R., Erdtel, M. Scholle, H. C., Kaiser, W. A., Mentzel, H. J., and Reichenbach, J. R. (2010). Time-resolved functional $1 \mathrm{H} \mathrm{MR}$ spectroscopic detection of glutamate concentration changes in the brain during acute heat pain stimulation. Neuroimage 49, 1895-1902.

Haber, S. N., and Knutson, B. (2010) The reward circuit: linking primate anatomy and human imaging. $\mathrm{Neu}$ ropsychopharmacology 35, 4-26.

Hao, S., Dulake, M., Espero, E., Sternini, C., Raybould, H. E., and Rinaman, L. (2009). Central Fos expression and conditioned flavor avoidance in rats following intragastric administration of bitter taste receptor ligands. Am. J. Physiol. Regul. Integr. Comp. Physiol. 296, R528-R536.

Hayes, D. J., Clements, R., and Greenshaw, A. J. (2009). Effects of systemic and intra-nucleus accumbens 5HT2C receptor compounds on ventral tegmental area self-stimulation thresholds in rats. Psychopharmacology (Berl.) 203, 579-588.
Hayes, D. J., Hoang, J., and Greenshaw, A. J. (2010). The role of nucleus accumbens shell GABA receptors on ventral tegmental area intracranial self-stimulation and a potential role for the 5-HT2C receptor. J. Psychopharmacol. doi: 10.1177/0269881110389212. [Epub ahead of print].

Heidbreder, C. A., and Groenewegen, $\mathrm{H}$. J. (2003). The medial prefrontal cortex in the rat: evidence for a dorsoventral distinction based upon functional and anatomical characteristics. Neurosci. Biobehav. Rev. 27, 555-579.

Herpertz, S. C., Dietrich, T. M., Wenning, B., Krings, T., Erberich, S. G., Willmes, K., Thron, A., and Sass, H. (2001). Evidence of abnormal amygdala functioning in borderline personality disorder: a functional MRI study. Biol. Psychiatry 50 292-298.

Herwig, U., Abler, B., Walter, H., and Erk, S. (2007). Expecting unpleasant stimuli - an fMRI study. Psychiatry Res. 154, 1-12.

Hoffman, K. L., Gothard, K. M., Schmid, M. C., and Logothetis, N. K. (2007). Facial-expression and gaze-selective responses in the monkey amygdala. Curr. Biol. 17, 766-772.

Holland, P. C., and Gallagher, M. (2004). Amygdala-frontal interactions and reward expectancy. Curr. Opin. Neurobiol. 14, 148-155.

Hosokawa, T., Kato, K., Inoue, M., and Mikami, A. (2007). Neurons in the macaque orbitofrontal cortex code relative preference of both rewarding and aversive outcomes. Neurosci. Res. 57, 434-445.

Hsieh, J. C., Stahle-Backdahl, M., Hagermark, O., Stone-Elander, S., Rosenquist, G., and Ingvar, M. (1996). Traumatic nociceptive pain activates the hypothalamus and the periaqueductal gray: a positron emission tomography study. Pain 64 303-314.

Inui-Yamamoto, C., Yoshioka, Y., Inui, T., Sasaki, K. S., Ooi, Y., Ueda, K., Seiyama, A., and Ohzawa, I. (2010). The brain mapping of the retrieval of conditioned taste aversion memory using manganese-enhanced magnetic resonance imaging in rats. Neuroscience 167, 199-204.

Jensen, J., Mcintosh, A. R., Crawley, A. P., Mikulis, D. J., Remington, G., and Kapur, S. (2003). Direct activation of the ventral striatum in anticipation of aversive stimuli. Neuron 40 , 1251-1257.

Jensen, J., Willeit, M., Zipursky, R. B., Savina, I., Smith, A. J., Menon, M., Crawley, A. P., and Kapur, S. (2008). The formation of abnormal associations in schizophrenia: neural and behavioral evidence. Neuropsychopharmacology 33, 473-479.

Jhou, T. (2005). Neural mechanisms of freezing and passive aversive behaviors. J. Comp. Neurol. 493, 111-114.

Jhou, T. C., Fields, H. L., Baxter, M. G., Saper, C. B., and Holland, P. C. (2009). The rostromedial tegmental nucleus (RMTg), a GABAergic afferent to midbrain dopamine neurons, encodes aversive stimuli and inhibits motor responses. Neuron 61, 786-800.

Johnson, L. R., Hou, M., Prager, E. M., and Ledoux, J. E. (2011). Regulation of the fear network by mediators of stress: norepinephrine alters the balance between cortical and subcortical afferent excitation of the lateral amygdala. Front. Behav. Neu rosci. 5:23. doi: 10.3389/fnbeh.2011. 00023

Johnson, P. L., Fitz, S. D., Hollis, J. H., Moratalla, R., Lightman, S. L., Shekhar, A., and Lowry, C. A. (2010a). Induction of c-Fos in 'panic/defence'-related brain circuits following brief hypercarbic gas exposure. J. Psychopharmacol. 25, 26-36.

Johnson, Z. V., Revis, A. A., Burdick, M. A., and Rhodes, J. S. (2010b). A similar pattern of neuronal Fos activation in 10 brain regions following exposure to reward- or aversionassociated contextual cues in mice. Physiol. Behav. 99, 412-418.

Jovanovic, T., Norrholm, S. D., Blanding, N. Q., Phifer, J. E., Weiss, T., Davis, M., Duncan, E., Bradley, B., and Ressler, K. (2010). Fear potentiation is associated with hypothalamic-pituitary-adrenal axis function in PTSD. Psychoneuroendocrinology 35, 846-857.

Kanske, P., Heissler, J., Schonfelder, S., Bongers, A., and Wessa, M. (2011). How to regulate emotion? Neural networks for reappraisal and distraction. Cereb. Cortex 21, 1379-1388.

Kaplan, G. B., Heinrichs, S. C., and Carey, R. J. (2010). Treatment of addiction and anxiety using extinction approaches: neural mechanisms and their treatment implications. Pharmacol. Biochem. Behav. 97, 619625.

Kawasaki, H., Adolphs, R., Oya, H., Kovach, C., Damasio, H., Kaufman, O., and Howard, M. III. (2005) Analysis of single-unit responses to emotional scenes in human ventromedial prefrontal cortex. J. Cogn. Neurosci. 17, 1509-1518.

Kienast, T., Hariri, A. R., Schlagenhauf, F., Wrase, J., Sterzer, P., Buchholz, H. G., Smolka, M. N., Grunder, G., Cumming, P., Kumakura, 
Y., Bartenstein, P., Dolan, R. J., and Heinz, A. (2008). Dopamine in amygdala gates limbic processing of aversive stimuli in humans. Nat. Neurosci. 11, 1381-1382.

Klucken, T., Kagerer, S., Schweckendiek, J., Tabbert, K., Vaitl, D., and Stark, R. (2009). Neural, electrodermal and behavioral response patterns in contingency aware and unaware subjects during a picture-picture conditioning paradigm. Neuroscience 158, 721-731.

Kober, H., Barrett, L. F., Joseph, J., BlissMoreau, E., Lindquist, K., and Wager, T. D. (2008). Functional grouping and cortical-subcortical interactions in emotion: a meta-analysis of neuroimaging studies. Neuroimage 42, 998-1031.

Koh, M. T., and Bernstein, I. L. (2005). Mapping conditioned taste aversion associations using c-Fos reveals a dynamic role for insular cortex. Behav. Neurosci. 119, 388-398.

Kong, J., Tu, P. C., Zyloney, C., and Su, T. P. (2010). Intrinsic functional connectivity of the periaqueductal gray, a resting fMRI study. Behav. Brain Res. 211, 215-219.

Kurth, F., Zilles, K., Fox, P. T., Laird, A. R., and Eickhoff, S. B. (2010). A link between the systems: functional differentiation and integration within the human insula revealed by metaanalysis. Brain Struct. Funct. 214, 519-534.

Kwon, B., Goltz, M., and Houpt, T. A. (2008). Expression of AP-1 family transcription factors in the amygdala during conditioned taste aversion learning: role for Fra-2. Brain Res. 1207, 128-141.

Labar, K. S., Gatenby, J. C., Gore, J. C., Ledoux, J. E., and Phelps, E. A. (1998). Human amygdala activation during conditioned fear acquisition and extinction: a mixed-trial fMRI study. Neuron 20, 937-945.

Lamprea, M. R., Cardenas, F. P., Vianna, D. M., Castilho, V.M., Cruz-Morales, S. E., and Brandao, M. L. (2002). The distribution of fos immunoreactivity in rat brain following freezing and escape responses elicited by electrical stimulation of the inferior colliculus. Brain Res. 950, 186-194.

Ledoux, J. E., Cicchetti, P., Xagoraris, A., and Romanski, L. M. (1990). The lateral amygdaloid nucleus: sensory interface of the amygdala in fear conditioning. J. Neurosci. 10, 1062-1069.

Lehner, M., Taracha, E., Skorzewska, A., Turzynska, D., Sobolewska, A., Maciejak, P., Szyndler, J., Hamed, A., Bidzinski, A., Wislowska-Stanek, A., and Plaznik, A. (2008). Expression of c-Fos and CRF in the brains of rats differing in the strength of a fear response. Behav. Brain Res. 188, 154-167.

Lei, L. G., Sun, S., Gao, Y. J., Zhao, Z. Q., and Zhang, Y. Q. (2004a). NMDA receptors in the anterior cingulate cortex mediate painrelated aversion. Exp. Neurol. 189, 413-421.

Lei, L. G., Zhang, Y. Q., and Zhao, Z. Q. (2004b). Pain-related aversion and fos expression in the central nervous system in rats. Neuroreport 15 67-71.

Leknes, S., and Tracey, I. (2008). A common neurobiology for pain and pleasure. Nat. Rev. Neurosci. 9, 314-320.

Lemos, J. I., Resstel, L. B., and Guimaraes, F. S. (2010). Involvement of the prelimbic prefrontal cortex on cannabidiol-induced attenuation of contextual conditioned fear in rats. Behav. Brain Res. 207, 105-111.

Levita, L., Hare, T. A., Voss, H. U., Glover, G., Ballon, D. J., and Casey, B. J. (2009). The bivalent side of the nucleus accumbens. Neuroimage 44, 1178-1187.

Li, T. T., Ren, W. H., Xiao, X., Nan, J., Cheng, L. Z., Zhang, X. H., Zhao, Z. Q., and Zhang, Y. Q. (2009). NMDA $\mathrm{NR} 2 \mathrm{~A}$ and NR2B receptors in the rostral anterior cingulate cortex contribute to pain-related aversion in male rats. Pain 146, 183-193.

Liberzon, I., Zubieta, J. K., Fig, L. M., Phan, K. L., Koeppe, R. A., and Taylor, S. F. (2002). mu-Opioid receptors and limbic responses to aversive emotional stimuli. Proc. Natl. Acad. Sci. U.S.A. 99, 7084-7089.

Lim, L. W., Temel, Y., Visser-Vandewalle, V., Blokland, A., and Steinbusch, $\mathrm{H}$. (2009). Fos immunoreactivity in the rat forebrain induced by electrical stimulation of the dorsolateral periaqueductal gray matter. J. Chem. Neuroanat. 38, 83-96.

Liu, Z. H., Shin, R., and Ikemoto, S. (2008). Dual role of medial A10 dopamine neurons in affective encoding. Neuropsychopharmacology 33, 3010-3020.

Logothetis, N. K. (2008). What we can do and what we cannot do with fMRI. Nature 453, 869-878.

Lovero, K. L., Simmons, A. N., Aron, J. L., and Paulus, M. P. (2009). Anterior insular cortex anticipates impending stimulus significance. Neuroimage 45, 976-983.

Ludascher, P., Bohus, M., Lieb, K., Philipsen, A., Jochims, A., and Schmahl, C. (2007). Elevated pain thresholds correlate with dissociation and aversive arousal in patients with borderline personality disorder. Psychiatry Res. 149, 291-296.
Lutcke, H., Gevensleben, H., Albrecht, B., and Frahm, J. (2009). Brain networks involved in early versus late response anticipation and their relation to conflict processing. J. Cogn. Neurosci. 21, 2172-2184.

Machado, C. J., and Bachevalier, J. (2006). The impact of selective amygdala, orbital frontal cortex, or hippocampal formation lesions on established social relationships in rhesus monkeys (Macaca mulatta). Behav. Neurosci. 120, 761-786.

Machado, C. J., Emery, N. J., Mason, W. A., and Amaral, D. G. (2010). Selective changes in foraging behavior following bilateral neurotoxic amygdala lesions in rhesus monkeys. Behav. Neurosci. 124, 761-772.

Machado, C. J., Kazama, A. M., and Bachevalier, J. (2009). Impact of amygdala, orbital frontal, or hippocampal lesions on threat avoidance and emotional reactivity in nonhuman primates. Emotion 9, 147-163.

Malkani, S., and Rosen, J. B. (2000) Induction of NGFI-B mRNA following contextual fear conditioning and its blockade by diazepam. Brain Res. Mol. Brain Res. 80, 153-165.

Markowitsch, H. J. (1998). Differential contribution of right and left amygdala to affective information processing. Behav. Neurol. 11, 233-244.

Matsumoto, M., and Hikosaka, O. (2009a). Representation of negative motivational value in the primate lateral habenula. Nat. Neurosci. 12 , 77-84.

Matsumoto, M., and Hikosaka, O. (2009b). Two types of dopamine neuron distinctly convey positive and negative motivational signals. Nature 459, 837-841.

McCabe, C., Cowen, P. J., and Harmer, C. J. (2009). Neural representation of reward in recovered depressed patients. Psychopharmacology (Berl.) 205, 667-677.

McCabe, C., Mishor, Z., Cowen, P. J., and Harmer, C. J. (2010). Diminished neural processing of aversive and rewarding stimuli during selective serotonin reuptake inhibitor treatment. Biol. Psychiatry 67, 439-445.

Mechias, M. L., Etkin, A., and Kalisch, R. (2010). A meta-analysis of instructed fear studies: implications for conscious appraisal of threat. Neuroimage 49, 1760-1768.

Mediavilla, C., Bernal, A., and Puerto, A. (2007). Taste aversion learning induced $\mathrm{c}$-fos expression in the nucleus of the solitary tract after spontaneous flavor intake: role of the inter-stimulus interval. Neurobiol. Learn. Mem. 88, 264-268.

Menon, M., Jensen, J., Vitcu, I., GraffGuerrero, A., Crawley, A., Smith, M. A., and Kapur, S. (2007). Temporal difference modeling of the blood-oxygen level dependent response during aversive conditioning in humans: effects of dopaminergic modulation. Biol. Psychiatry 62, 765-772.

Menon, V., and Uddin, L. Q. (2010). Saliency, switching, attention and control: a network model of insula function. Brain Struct. Funct. 214 655-667.

Meriau, K., Wartenburger, I., Kazzer, P., Prehn, K., Villringer, A., Van Der Meer, E., and Heekeren, H. R. (2009). Insular activity during passive viewing of aversive stimuli reflects individual differences in state negative affect. Brain Cogn. 69, 73-80.

Mickley, G. A., Kenmuir, C. L., Mcmullen, C. A., Yocom, A. M., Valentine, E. L., Dengler-Crish, C. M., Weber, B., Wellman, J. A., and Remmers-Roeber, D. R. (2004). Dynamic processing of taste aversion extinction in the brain. Brain Res. 1016, 79-89.

Milad, M. R., Quirk, G. J., Pitman, R. K., Orr, S. P., Fischl, B., and Rauch, S. L. (2007). A role for the human dorsal anterior cingulate cortex in fear expression. Biol. Psychiatry 62, 1191-1194.

Mirenowicz, J., and Schultz, W. (1996). Preferential activation of midbrain dopamine neurons by appetitive rather than aversive stimuli. Nature $379,449-451$.

Misslin, R. (2003). The defense system of fear: behavior and neurocircuitry. Neurophysiol. Clin. 33, 55-66.

Mobbs, D., Petrovic, P., Marchant, J. L., Hassabis, D., Weiskopf, N. Seymour, B., Dolan, R. J., and Frith, C. D. (2007). When fear is near: threat imminence elicits prefrontal-periaqueductal gray shifts in humans. Science 317 1079-1083.

Morrison, S. E., and Salzman, C. D. (2009). The convergence of information about rewarding and aversive stimuli in single neurons. J. Neurosci. 29, 11471-11483.

Morrison, S. E., and Salzman, C. D. (2010). Re-valuing the amygdala. Curr. Opin. Neurobiol. 20 221-230.

Mouraux, A., Diukova, A., Lee, M. C., Wise, R. G., and Iannetti, G. D. (2011). A multisensory investigation of the functional significance of the "pain matrix." Neuroimage 54, 2237-2249. 
Mullins, P. G., Rowland, L. M., Jung, R. E., and Sibbitt, W. L. Jr. (2005). A novel technique to study the brain's response to pain: proton magnetic resonance spectroscopy. Neuroimage 26, 642-646.

Murray, E. A. (2007). The amygdala, reward and emotion. Trends Cogn. Sci. (Regul. Ed.) 11, 489-497.

Navarro, M., Spray, K. J., Cubero, I., Thiele, T. E., and Bernstein, I. L. (2000). cFos induction during conditioned taste aversion expression varies with aversion strength. Brain Res. 887, 450-453.

Nikolaev, E., Kaczmarek, L., Zhu, S. W., Winblad, B., and Mohammed, A. H. (2002). Environmental manipulation differentially alters c-Fos expression in amygdaloid nuclei following aversive conditioning. Brain Res. 957, 91-98.

Nikulina, E. M., Arrillaga-Romany, I., Miczek, K. A., and Hammer, R. P. Jr. (2008). Long-lasting alteration in mesocorticolimbic structures after repeated social defeat stress in rats: time course of mu-opioid receptor mRNA and FosB/DeltaFosB immunoreactivity. Eur. J. Neurosci. 27, 2272-2284.

Norrholm, S. D., Jovanovic, T., Olin, I. W., Sands, L. A., Karapanou, I., Bradley, B., and Ressler, K. J. (2010). Fear extinction in traumatized civilians with posttraumatic stress disorder: relation to symptom severity. Biol. Psychiatry 69, 556-563.

Northoff, G., Duncan, N. W., and Hayes, D. J. (2010). The brain and its resting state activity experimental and methodological implications. Prog. Neurobiol. 92, 593-600.

Ongur, D., and Price, J. L. (2000). The organization of networks within the orbital and medial prefrontal cortex of rats, monkeys and humans. Cereb. Cortex 10, 206-219.

Panksepp, J. (1998). Affectvie Neuroscience: Tho Foundations of Human and Animal Emotions. New York: Oxford University Press.

Parsons, R. G., and Davis, M. (2011). Temporary disruption of fearpotentiated startle following PKMzeta inhibition in the amygdala. Nat. Neurosci. 14, 295-296.

Paton, J. J., Belova, M. A., Morrison, S. E., and Salzman, C. D. (2006). The primate amygdala represents the positive and negative value of visual stimuli during learning. Nature 439, 865-870.

Phan, K. L., Liberzon, I., Welsh, R. C., Britton, J. C., and Taylor, S. F. (2003). Habituation of rostral anterior cingulate cortex to repeated emotionally salient pictures. Neuropsychopharmacology 28, 1344-1350.

Ploghaus, A., Tracey, I., Gati, J. S., Clare, S., Menon, R. S., Matthews, P. M. and Rawlins, J. N. (1999). Dissociating pain from its anticipation in the human brain. Science 284, 1979-1981.

Prevost, C., Mccabe, J. A., Jessup, R. K., Bossaerts, P., and O'doherty, J. P. (2011). Differentiable contributions of human amygdalar subregions in the computations underlying reward and avoidance learning. Eur. J. Neurosci. 34, 134-145.

Radwanska, K., Nikolaev, E., Knapska, E., and Kaczmarek, L. (2002). Differential response of two subdivisions of lateral amygdala to aversive conditioning as revealed by c-Fos and P-ERK mapping. Neuroreport 13, 2241-2246.

Rilling, J. K., Sanfey, A. G., Aronson, J. A., Nystrom, L. E., and Cohen, J. D. (2004). The neural correlates of theory of mind within interpersonal interactions. Neuroimage 22, 1694-1703.

Rolls, E. T. (2008). Functions of the orbitofrontal and pregenual cingulate cortex in taste, olfaction, appetite and emotion. Acta Physiol. Hung. 95, 131-164.

Rolls, E. T., Grabenhorst, F., and Parris, B. A. (2008). Warm pleasant feelings in the brain. Neuroimage 41, 1504-1513.

Rolls, E. T., Kringelbach, M. L., and De Araujo, I. E. (2003). Different representations of pleasant and unpleasant odours in the human brain. Eur. J. Neurosci. 18, 695-703.

Roseboom, P. H., Nanda, S. A., Bakshi, V. P., Trentani, A., Newman, S. M., and Kalin, N. H. (2007). Predator threat induces behavioral inhibition, pituitary-adrenal activation and changes in amygdala CRF-binding protein gene expression. Psychoneuroendocrinology 32 44-55.

Sadananda, M., Wohr, M., and Schwarting, R. K. (2008). Playback of 22-kHz and $50-\mathrm{kHz}$ ultrasonic vocalizations induces differential c-fos expression in rat brain. Neurosci. Lett. 435, 17-23.

Salas, R., Baldwin, P., De Biasi, M., and Montague, P. R. (2010). BOLD responses to negative reward prediction errors in human habenula. Front. Hum. Neurosci. 4:36. doi: 10.3389/fnhum.2010.00036

Salchner, P., Sartori, S. B., Sinner, C., Wigger, A., Frank, E., Landgraf, R., and Singewald, N. (2006). Airjet and FG-7142-induced Fos expression differs in rats selectively bred for high and low anxiety-related behavior. Neuropharmacology 50, 1048-1058.

Salimi-Khorshidi, G., Smith, S. M., Keltner, J. R., Wager, T. D., and Nichols, T. E. (2009). Meta-analysis of neuroimaging data: a comparison of image-based and coordinate-based pooling of studies. Neuroimage 45, 810-823.

Sarinopoulos, I., Grupe, D. W., Mackiewicz, K. L., Herrington, J. D., Lor, M., Steege, E. E., and Nitschke, J. B. (2009). Uncertainty during anticipation modulates neural responses to aversion in human insula and amygdala. Cereb. Cortex 20, 929-940.

Scott, D. J., Heitzeg, M. M., Koeppe, R. A., Stohler, C. S., and Zubieta, J. K. (2006). Variations in the human pain stress experience mediated by ventral and dorsal basal ganglia dopamine activity. J. Neurosci. 26, 10789-10795.

Seubert, J., Kellermann, T., Loughead, J., Boers, F., Brensinger, C., Schneider, F., and Habel, U. (2010a). Processing of disgusted faces is facilitated by odor primes: a functional MRI study. Neuroimage 53 746-756.

Seubert, J., Loughead, J., Kellermann, T., Boers, F., Brensinger, C. M. and Habel, U. (2010b). Multisensory integration of emotionally valenced olfactory-visual information in patients with schizophrenia and healthy controls. J. Psychiatry Neurosci. 35, 185-194.

Seymour, B., Singer, T., and Dolan, R. (2007). The neurobiology of punishment. Nat. Rev. Neurosci. 8, 300-311.

Shabel, S. J., and Janak, P. H. (2009). Substantial similarity in amygdala neuronal activity during conditioned appetitive and aversive emotional arousal. Proc. Natl. Acad. Sci. U.S.A. 106, 15031-15036.

Shumake, J., and Gonzalez-Lima, F. (2003). Brain systems underlying susceptibility to helplessness and depression. Behav. Cogn. Neurosci. Rev. 2, 198-221.

Simons, R. F. (2010). The way of our errors: theme and variations. Psychophysiology 47, 1-14.

Smith, S. M., and Vale, W. W. (2006) The role of the hypothalamicpituitary-adrenal axis in neuroendocrine responses to stress. Dialogues Clin. Neurosci. 8, 383-395.

St Andre, J., Albanos, K., and Reilly, S. (2007). C-fos expression in the rat brain following lithium chlorideinduced illness. Brain Res. 1135 , 122-128.
Strigo, I. A., Simmons, A. N., Matthews, S. C., Craig, A. D., and Paulus, M. P. (2008). Association of major depressive disorder with altered functional brain response during anticipation and processing of heat pain. Arch. Gen. Psychiatry 65, 1275-1284.

Tindell, A. J., Smith, K. S., Pecina, S., Berridge, K. C., and Aldridge, J. W. (2006). Ventral pallidum firing codes hedonic reward: when a bad taste turns good. J. Neurophysiol. 96, 2399-2409.

Tops, M., Russo, S., Boksem, M. A., and Tucker, D. M. (2009). Serotonin: modulator of a drive to withdraw. Brain Cogn. 71, 427-436.

Tremeau, F., Brady, M., Saccente, E., Moreno, A., Epstein, H., Citrome, L., Malaspina, D., and Javitt, D. (2008). Loss aversion in schiz ophrenia. Schizophr. Res. 103, 121-128.

Vertes, R. P. (2006). Interactions among the medial prefrontal cortex, hippocampus and midline thalamus in emotional and cognitive processing in the rat. Neuroscience 142, $1-20$

Vianna, D. M., Borelli, K. G., FerreiraNetto, C., Macedo, C. E., and Brandao, M. L. (2003). Fos-like immunoreactive neurons following electrical stimulation of the dorsal periaqueductal gray at freezing and escape thresholds. Brain Res. Bull. 62, 179-189.

Wager, T. D., Lindquist, M. A., Nichols, T. E., Kober, H., and Van Snellenberg, J. X. (2009). Evaluating the consistency and specificity of neuroimaging data using meta-analysis. Neuroimage 45, S210-S221.

Walker, D. L., Toufexis, D. J., and Davis, M. (2003). Role of the bed nucleus of the stria terminalis versus the amygdala in fear, stress, and anxiety. Eur. J. Pharmacol. 463, 199-216.

Walton, M. E., Behrens, T. E., Buckley, M. J., Rudebeck, P. H., and Rushworth, M. F. (2010). Separable learning systems in the macaque brain and the role of orbitofrontal cortex in contingent learning. Neuron 65, 927-939.

Walton, M. E., Croxson, P. L., Behrens, T. E., Kennerley, S. W., and Rushworth, M. F. (2007). Adaptive decision making and value in the anterior cingulate cortex. Neuroimage 36 Suppl 2, T142-T154.

Wang, H., Ren, W. H., Zhang, Y. Q., and Zhao, Z. Q. (2005). GABAergic disinhibition facilitates polysynaptic excitatory transmission in rat anterior cingulate cortex. Biochem. Biophys. Res. Commun. 338, 1634-1639. 
Hayes and Northoff

Translational aversion-related network

Weiss, F., Ciccocioppo, R., Parsons, L. H., Katner, S., Lu, X., Zorrilla, E. P., Valdez, G. R., Ben-Shahar, O., Angeletti, S., and Richter, R. R. (2001). Compulsive drug-seeking behavior and relapse. Neuroadaptaton, stress, and conditioning factors. Ann. N. Y. Accad. Sci. 937, 1-26.

Wheeler, R. A., Twining, R. C., Jones, J. L., Slater, J. M., Grigson, P. S., and Corelli, R. M. (2008). Behavioral and electrophysiological indices of negative affect predict cocaine self-administration. Neuron 57, 774-785.

Wilkins, E. E., and Bernstein, I. L. (2006). Conditioning method determines patterns of c-fos expression following novel taste-illness pairing. Behave. Brain Res. 169, 93-97.

Wise, R. A. (2004). Dopamine, learning and motivation. Nat. Rev. Neurosci. 5, 483-494.
Wright, P., Albarracin, D., Brown, R. D., Li, H., He, G., and Lu, Y. (2008). Dissociated responses in the amygdala and orbitofrontal cortex to bottomup and top-down components of emotional evaluation. Neuroimage 39, 894-902.

Xue, G., Lu, Z., Levin, I. P., Weller, J. A., Li, X., and Bechara, A. (2009). Functional dissociation of risk and reward processing in the medial prefrontal cortex. Cered. Cortex 19, 1019-1027.

Yasoshima, Y., Scott, T. R., and Yamamoto, T. (2006). Memorydependent c-Fos expression in the nucleus accumbens and extended amygdala following the expression of a conditioned taste aversive in the rat. Neuroscience 141, 35-45.

Yasoshima, Y., Scott, T. R., and Yamamoto, T. (2007). Differential activation of anterior and midline thalamic nuclei following retrieval of aversively motivated learning tasks. Neuroscience 146, 922-930.

Zald, D. H., and Pardo, J. V. (2002). The neural correlates of aversive auditory stimulation. Neuroimage 16, 746-753.

Zanoveli, J. M., Ferreira-Netto, C., and Brandao, M. L. (2007). Conditioned place aversion organized in the dorsal periaqueductal gray recruits the laterodorsal nucleus of the thalamus and the basolateral amygdala. Exp. Neurol. 208, 127-136.

Rink, C. F., Pagnoni, G., MartinSkurski, M. E., Chappelow, J. C., and Berns, G. S. (2004). Human strianal responses to monetary reward depend on saliency. Neuron 42, 509-517.

Conflict of Interest Statement: The authors declare that the research was conducted in the absence of any commercial or financial relationships that could be construed as a potential conflict of interest.

Received: 06 July 2011; paper pending published: 07 August 2011; accepted: 19 August 2011; published online: 03 Ottobor 2011.

Citation: Hayes DJ and Northoff $G$ (2011) Identifying a network of brain regions involved in aversion-related processing: a cross-species translational investigation. Front. Integr. Neurosci. 5:49. dor: 10.3389/fnint.2011.00049 Copyright (c) 2011 Hayes and Northoff. This is an open-access article subject to a nonexclusive license between the authors and Frontiers Media SA, which permits use, distribution and reproducion in other forums, provided the original authors and source are credited and other Frontiers conditions are complied with.

Frontiers in Integrative Neuroscience

www.frontiersin.org

October 2011 | Volume 5 | Article 49 | 20 


\section{REFERENCES USED IN META-ANALYSIS}

Abler, B., Erk, S., Herwig, U., and Walter, H. (2007). Anticipation of aversive stimuli activates extended amygdala in unipolar depression. J. Psychiatr. Res. 41, 511-522.

Blood, A. J., Zatorre, R. J., Bermudez, P. and Evans, A. C. (1999). Emotional responses to pleasant and unpleasant music correlate with activity in paralimbic brain regions. Nat. Neurosci. 2, 382-387.

Botvinick, M., Jha, A. P., Bylsma, L. M., Fabian, S. A., Solomon, P. E., and Prkachin, K. M. (2005). Viewing facial expressions of pain engages cortical areas involved in the direct experience of pain. Neuroimage 25, 312-319.

Buchel, C., Bornhovd, K., Quante, M., Glauche, V., Bromm, B., and Weiller, C. (2002). Dissociable neural responses related to pain intensity, stimulus intensity, and stimulus awareness within the anterior cingulate cortex: a parametric single-trial laser functional magnetic resonance imaging study. J. Neurosci. 22, 970-976.

Buchel, C., Dolan, R. J., Armony, J. L., and Friston, K. J. (1999). Amygdalahippocampal involvement in human aversive trace conditioning revealed through event-related functional magnetic resonance imaging. J. Neurosci. 19, 10869-10876.

Frings, M., Maschke, M., Erichsen, M., Jentzen, W., Muller, S. P., Kolb, F. P., Diener, H. C., and Timmann, D. (2002). Involvement of the human cerebellum in fearconditioned potentiation of the acoustic startle response: a PET study. Neuroreport 13, 1275-1278.

Garrett, A.S., and Maddock, R. J. (2006). Separating subjective emotion from the perception of emotion-inducing stimuli: an fMRI study. Neuroimage 33, 263-274.

Gottfried, J. A., O'doherty, J., and Dolan, R. J. (2002). Appetitive and aversive olfactory learning in humans studied using event-related functional magnetic resonance imaging. J. Neurosci. 22, 10829-10837.

Grabenhorst, F., Rolls, E. T., Margot, C., Da Silva, M. A., and Velazco, M. I. (2007). How pleasant and unpleasant stimuli combine in different brain regions: odor mixtures. J. Neurosci. 27, 13532-13540.

Hamann, S., and Mao, H. (2002). Positive and negative emotional verbal stimuli elicit activity in the left amygdala. Neuroreport 13, 15-19.

Hamann, S. B., Ely, T. D., Hoffman, J. M., and Kilts, C. D. (2002). Ecstasy and agony: activation of the human amygdala in positive and negative emotion. Psychol. Sci. 13, 135-141.

Herpertz, S. C., Dietrich, T. M., Wenning, B., Krings, T., Erberich, S. G., Willmes, K., Thron, A., and Sass, H. (2001). Evidence of abnormal amygdala functioning in borderline personality disorder: a functional MRI study. Biol. Psychiatry 50, 292-298.

Herwig, U., Abler, B., Walter, H., and Erk, S. (2007). Expecting unpleasant stimuli - an fMRI study. Psychiatry Res. 154, 1-12.

Jensen, J., Mcintosh, A. R., Crawley, A. P., Mikulis, D. J., Remington, G., and Kapur, S. (2003). Direct activation of the ventral striatum in anticipation of aversive stimuli. Neuron 40, 1251-1257.

Klucken, T., Kagerer, S., Schweckendiek, J., Tabbert, K., Vaitl, D., and Stark, R. (2009). Neural, electrodermal and behavioral response patterns in contingency aware and unaware subjects during a picture-picture conditioning paradigm. Neuroscience 158 721-731.

Levita, L., Hare, T. A., Voss, H. U., Glover, G., Ballon, D. J., and Casey, B. J. (2009). The bivalent side of the nucleus accumbens. Neuroimage 44 , 1178-1187.

Liberzon, I., Phan, K. L., Decker, L. R. and Taylor, S. F. (2003). Extended amygdala and emotional salience: a PET activation study of positive and negative affect. Neuropsychopharmacology 28, 726-733.

Liberzon, I., Taylor, S. F., Fig, L. M., Decker, L. R., Koeppe, R. A., and Minoshima, S. (2000). Limbic activation and psychophysiologic responses to aversive visual stimuli. Interaction with cognitive task. Neuropsychopharmacology 23, 508-516.

Liberzon, I., Zubieta, J. K., Fig, L. M. Phan, K. L., Koeppe, R. A., and Taylor, S. F. (2002). mu-Opioid receptors and limbic responses to aversive emotional stimuli. Proc. Natl. Acad. Sci. U.S.A. 99, 7084-7089.

Maddock, R. J., Garrett, A. S., and Buonocore, M. H. (2003). Posterior cingulate cortex activation by emotional words: fMRI evidence from a valence decision task. Hum. Brain Mapp. 18, 30-41.

Meriau, K., Wartenburger, I., Kazzer, P. Prehn, K., Villringer, A., Van Der Meer, E., and Heekeren, H. R. (2009). Insular activity during passive viewing of aversive stimuli reflects individual differences in state negative affect. Brain Cogn. 69, 73-80.

Meseguer, V., Romero, M. J., BarrosLoscertales, A., Belloch, V., BoschMorell, F., Romero, J., and Avila, C. (2007). Mapping the apetitive and aversive systems with emotional pictures using a block-design fMRI procedure. Psicothema 19, 483-488.

Mirz, F., Gjedde, A., Sodkilde-Jrgensen, H., and Pedersen, C. B. (2000). Functional brain imaging of tinnituslike perception induced by aversive auditory stimuli. Neuroreport 11 , 633-637.

Nitschke, J. B., Sarinopoulos, I., Mackiewicz, K. L., Schaefer, H. S. and Davidson, R. J. (2006). Functional neuroanatomy of aversion and its anticipation. Neuroimage 29 106-116.

O'doherty, J. P., Deichmann, R., Critchley, H. D., and Dolan, R. J. (2002). Neural responses during anticipa- tion of a primary taste reward. Neuron 33, 815-826.

Phan, K. L., Liberzon, I., Welsh, R. C., Britton, J. C., and Taylor, S. F. (2003). Habituation of rostral anterior cingulate cortex to repeated emotionally salient pictures. Neuropsychopharmacology 28, 1344-1350.

Rolls, E. T. (2008). Functions of the orbitofrontal and pregenual cingulate cortex in taste, olfaction, appetite and emotion. Acta Physiol. Hung. 95, 131-164.

Rolls, E. T., Kringelbach, M. L. and De Araujo, I. E. (2003) Different representations of pleasant and unpleasant odours in the human brain. Eur. J. Neurosci. 18, 695-703.

Shirao, N., Okamoto, Y., Mantani, T., and Yamawaki, S. (2005). Gender differences in brain activity generated by unpleasant word stimuli concerning body image: an fMRI study. Br. J. Psychiatry 186, 48-53.

Straube, T., Weiss, T., Mentzel, H. J., and Miltner, W. H. (2007). Time course of amygdala activation during aversive conditioning depends on attention. Neuroimage 34, 462-469.

Tabbert, K., Stark, R., Kirsch, P., and Vaitl, D. (2005). Hemodynamic responses of the amygdala, the orbitofrontal cortex and the visual cortex during a fear conditioning paradigm. Int. J. Psychophysiol. 57, $15-23$.

Taylor, S. F., Liberzon, I., and Koeppe, R. A. (2000). The effect of graded aversive stimuli on limbic and visual activation. Neuropsychologia 38, 1415-1425.

Taylor, S. F., Phan, K. L., Decker, L. R., and Liberzon, I. (2003). Subjective rating of emotionally salient stimuli modulates neural activity. Neuroimage 18, 650-659.

Zald, D. H., and Pardo, J. V. (2002). The neural correlates of aversive auditory stimulation. Neuroimage 16, 746-753. 